\title{
Advances in Coupled Safety Modeling Using Systems Analysis and High-Fidelity Methods
}

T. H. Fanning and J. W. Thomas

Nuclear Engineering Division

Argonne National Laboratory

May 31, 2010

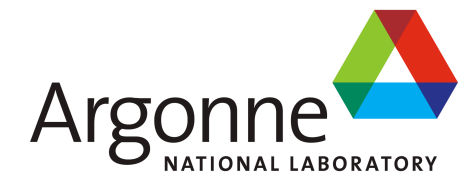




\begin{abstract}
About Argonne National Laboratory
Argonne is a U.S. Department of Energy laboratory managed by UChicago Argonne, LLC under contract DE-AC02-06CH11357. The Laboratory's main facility is outside Chicago, at 9700 South Cass Avenue, Argonne, Illinois 60439. For information about Argonne, see www.anl.gov.
\end{abstract}

\title{
Availability of This Report
}

This report is available, at no cost, at http://www.osti.gov/bridge. It is also available on paper to the U.S. Department of Energy and its contractors, for a processing fee, from:

U.S. Department of Energy

Office of Scientific and Technical Information

P.O. Box 62

Oak Ridge, TN 37831-0062

phone (865) 576-8401

fax (865) 576-5728

reports@adonis.osti.gov

\begin{abstract}
Disclaimer
This report was prepared as an account of work sponsored by an agency of the United States Government. Neither the United States Government nor any agency thereof, nor UChicago Argonne, LLC, nor any of their employees or officers, makes any warranty, express or implied, or assumes any legal liability or responsibility for the accuracy, completeness, or usefulness of any information, apparatus, product, or process disclosed, or represents that its use would not infringe privately owned rights. Reference herein to any specific commercial product, process, or service by trade name, trademark, manufacturer, or otherwise, does not necessarily constitute or imply its endorsement, recommendation, or favoring by the United States Government or any agency thereof. The views and opinions of document authors expressed herein do not necessarily state or reflect those of the United States Government or any agency thereof, Argonne National Laboratory, or UChicago Argonne, LLC.
\end{abstract}




\section{SUMMARY}

The potential for a sodium-cooled fast reactor to survive severe accident initiators with no damage has been demonstrated through whole-plant testing in EBR-II and FFTF. Analysis of the observed natural protective mechanisms suggests that they would be characteristic of a broad range of sodium-cooled fast reactors utilizing metal fuel. However, in order to demonstrate the degree to which new, advanced sodiumcooled fast reactor designs will possess these desired safety features, accurate, highfidelity, whole-plant dynamics safety simulations will be required.

One of the objectives of the advanced safety-modeling component of the Reactor IPSC is to develop a science-based advanced safety simulation capability by utilizing existing safety simulation tools coupled with emerging high-fidelity modeling capabilities in a multi-resolution approach. As part of this integration, an existing whole-plant systems analysis code has been coupled with a high-fidelity computational fluid dynamics code to assess the impact of high-fidelity simulations on safety-related performance.

With the coupled capabilities, it is possible to identify critical safety-related phenomenon in advanced reactor designs that cannot be resolved with existing tools. In this report, the impact of coupling is demonstrated by evaluating the conditions of outlet plenum thermal stratification during a protected loss of flow transient. Outlet plenum stratification was anticipated to alter core temperatures and flows predicted during natural circulation conditions. This effect was observed during the simulations.

What was not anticipated, however, is the far-reaching impact that resolving thermal stratification has on the whole plant. The high temperatures predicted at the IHX inlet due to thermal stratification in the outlet plenum forces heat into the intermediate system to the point that it eventually becomes a source of heat for the primary system. The results also suggest that flow stagnation in the intermediate system is possible, raising questions about the effectiveness of the intermediate decay heat removal systems in the design that was evaluated. Existing tools do not predict flow stagnation.

This work has demonstrated that with a proper coupling approach, a high-fidelity CFD tool can be used to resolve the important flow and temperature distributions throughout a plant while still maintaining the whole-plant safety analysis capabilities of a systems analysis code. 


\section{TABLE OF CONTENTS}

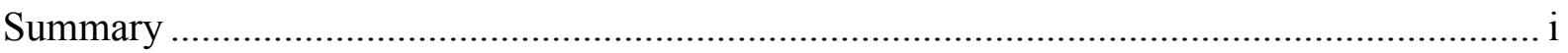

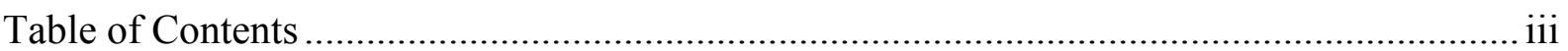

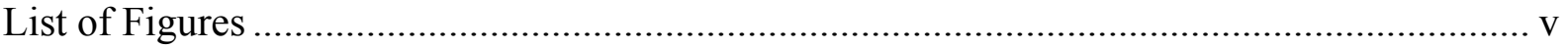

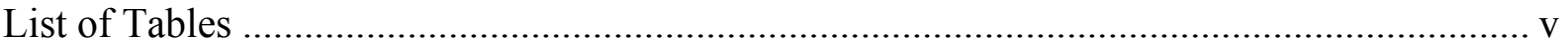

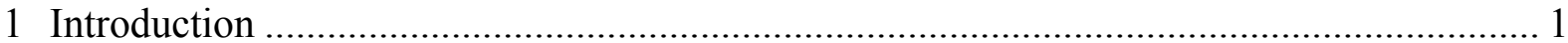

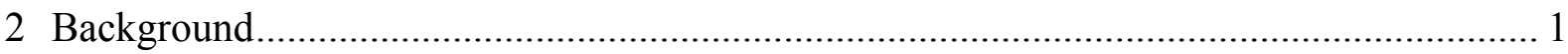

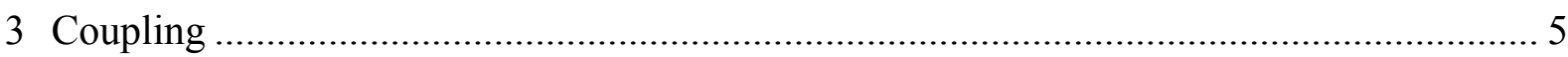

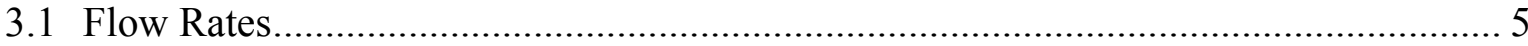

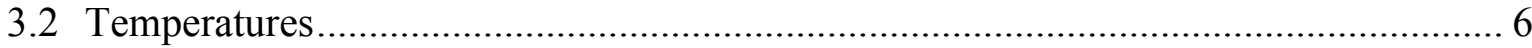

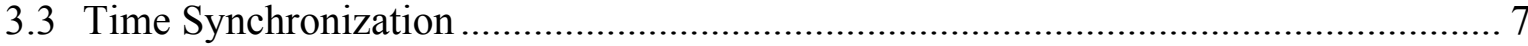

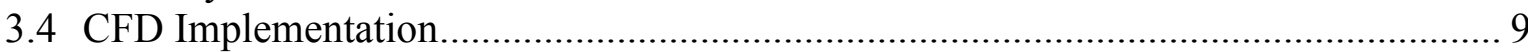

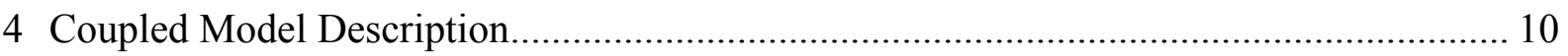

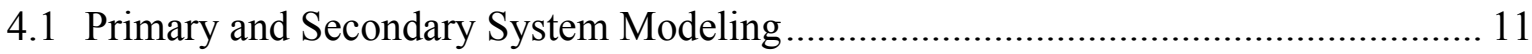

4.2 Outlet Plenum Geometry ………………………….............................................. 13

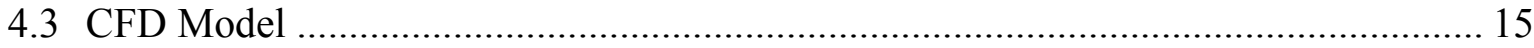

5 Coupled Model Results ......................................................................................... 17

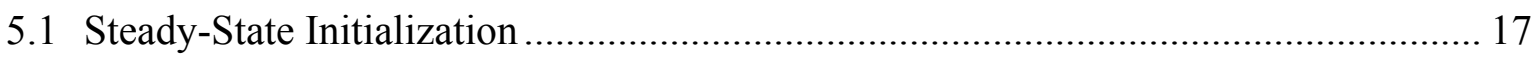

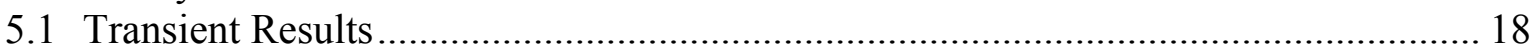

5.1.1 Outlet Plenum Temperature Distributions...................................................... 18

5.1.2 IHX Temperature and Flow....................................................................... 20

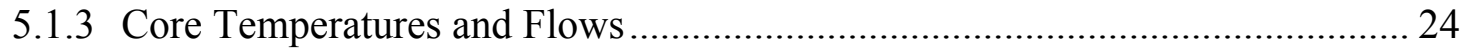

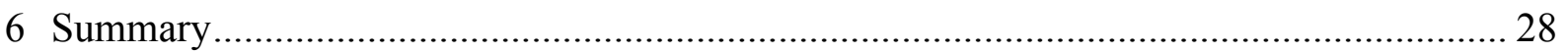

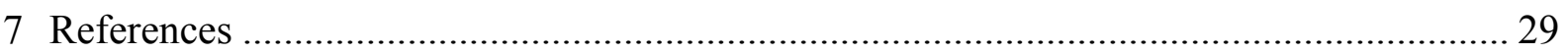




\section{LIST OF FIGURES}

Figure 1: Simplified Representation of the 4S Primary System (not to scale).

Figure 2: IHX Primary Inlet Temperatures With and Without Thermal Stratification in the SAS4A/SASSYS-1 Model Compared to the Results Predicted by CERES.

Figure 3: Comparison of Core Inlet and Outlet Coolant Temperatures between SAS4A/SASSYS-1 (Solid Lines, No Stratification) and CERES (Dashed Lines)......4

Figure 4: Time Step Hierarchy between Modules in SAS4A/SASSYS-1 and CFD ................... 8

Figure 5: PRIMAR-4 Network Model for the 4S Reactor...................................................... 11

Figure 6: Three-dimensional surface representation of the $4 \mathrm{~S}$ outlet plenum. ...........................14

Figure 7: Geometry for Axisymmetric STAR-CD Model of the 4S Plenum ............................15

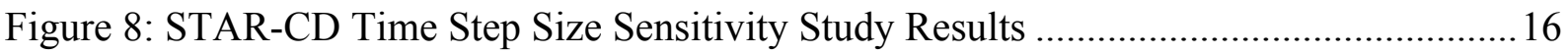

Figure 9: STAR-CD Predictions for Temperature at $t=0$........................................................ 19

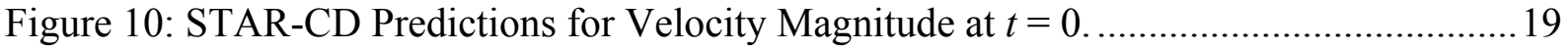

Figure 11: STAR-CD Predictions for Pressure, Relative to the IHX Inlet Boundary, at

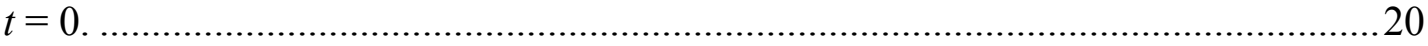

Figure 12: STAR-CD Prediction for Temperature Contours at Selected Times for One-

Way Coupling (top) and Full Coupling (bottom) Codes. ..........................................21

Figure 13: IHX Inlet and Outlet Temperatures for the Uncoupled Case...................................23

Figure 14: IHX Inlet and Outlet Temperatures for the Coupled Case......................................23

Figure 15: Normalized Primary and Secondary System Flow Rates for Both Coupled and Uncoupled Cases. Thermal stratification in the outlet plenum enhances primary system flow rates but causes flow stagnation in the secondary system......................24

Figure 16: Core Inlet and Outlet Temperatures for the Uncoupled Case. ................................25

Figure 17: Core Inlet and Outlet Temperatures for the Coupled Case. ...................................25

Figure 18: Core Inlet and Outlet Temperature Differences Between Coupled and

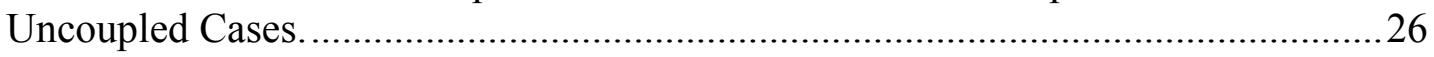

Figure 19: Core Channel Flow Rates for the Uncoupled Case. ............................................2

Figure 20: Core Channel Flow Rates for the Coupled Case......................................................2 27

Figure 21: Core Channel Flow Differences Between Coupled and Uncoupled Cases.............28

\section{LIST OF TABLES}

Table I: Flow Elements Used in the PRIMAR-4 Model for the 4S........................................12

Table II: Compressible Volumes Used in the PRIMAR-4 Model for the 4S. ............................13

Table III: Mapping of SAS4A/SASSYS-1 Channels to STAR-CD Inlet Regions in the Axisymmetric Model ........................................................................................... 16

Table IV: Initial Steady-State Conditions for the Protected Loss-of-Flow Accident ................18 


\section{Introduction}

Under the U.S. Department of Energy's Nuclear Energy Advanced Modeling and Simulation (NEAMS) Program, reactor integrated performance and safety codes (IPSC) are being developed within the SHARP (Simulation for High-efficiency Advanced Reactor Prototyping) framework.[1] High-fidelity, coupled neutron transport and thermal hydraulics capabilities are being developed to exploit advances in computers and software tools in order to facilitate reactor design optimization, provide increased assurance of performance and safety characteristics, and reduce the need for large scale integral experiments needed to characterize or validate reactor performance.

One of the objectives of the advanced safety-modeling component of the Reactor IPSC is to develop a science-based advanced safety simulation capability by utilizing existing safety simulation tools coupled with emerging high-fidelity modeling capabilities in a multiresolution approach. With the coupled capabilities, it is possible to identify critical safetyrelated phenomenon in advanced reactor designs that cannot be resolved with existing tools.

To support whole-plant safety analyses for realistic transients, an existing integral analysis capability has been coupled with a high-fidelity computational fluid dynamics (CFD) code to assess the impact of high-fidelity simulations on safety-related performance. In this report, impact of coupling is demonstrated by evaluating the conditions of thermal stratification during a protected loss of flow transient. Accurate determination of the thermal profile within reactor outlet plenums is important for the correct prediction of natural convection flow rates, which must be sufficient to ensure cooling during loss of flow transients.

In the sections that follow, the need for higher fidelity treatment in a reactor outlet plenum is explained, and the capabilities and limitations of existing tools are described.

Computational fluid dynamics (CFD) modeling capabilities are introduced that eliminate many of these limitations, and the coupling method between whole system and CFD models is presented. Results from the evaluation of thermal stratification during a protected loss of flow transient are compared, and the impact from including a high-fidelity treatment is assessed..

\section{Background}

Through a series of Shutdown Heat Removal Tests (SHRT) conducted in EBR-II, the potential for a sodium-cooled fast reactor to survive severe accident initiators with no damage has been demonstrated. These tests culminated in two tests of historical significance that were observed by an international audience in 1986: loss of flow from full power with failure to scram and loss of heat sink at full power with failure to scram.[2] Results from these tests illustrated that (a) natural reactivity feedback mechanisms were sufficient to reduce core power and (b) natural convection cooling was sufficient to remove heat during the transients. Analyses of the natural protective mechanisms suggest that they would be characteristic of a broad range of sodium-cooled fast reactors utilizing metal fuel.

Although sodium-cooled fast reactors have been successfully built and tested in the U.S. and throughout the world,[3] no fast reactor has operated in the U.S. in the fifteen years since EBR-II was shutdown. More importantly, the U.S. has not constructed a fast reactor in nearly 30 years. In addition to reestablishing the necessary industrial infrastructure, the development, 
testing, and licensing of a new, advanced fast reactor concept will likely require a significant base technology program that relies more heavily on modeling and simulation than has been done in the past. In order to demonstrate the degree to which advanced reactor designs will possess desired passive safety features, accurate, high-fidelity, whole-plant dynamics safety simulations will be required. These simulation tools will play a crucial role by providing confidence that component and system designs will satisfy established design limits and safety margins under a wide variety of operational, design basis, and beyond design basis transient conditions over the life cycle of a plant.

The potential impact of thermal stratification on natural circulation flow rates was highlighted in a recent comparative study between the SAS4A/SASSYS-1 safety analysis code used in the United States[4] and the CERES safety analysis code used by CRIEPI in Japan.[5] The comparison was made for the purpose of verification of the CERES code and was based on analysis of the August 2006 design of the $4 \mathrm{~S}$ concept. A simplified representation of the $4 \mathrm{~S}$ primary system geometry is shown in Figure 1. In this design, coolant flows through the core to an extended outlet plenum that is approximately eleven meters tall. During low flow conditions, significant thermal stratification can occur in the outlet plenum. Comparisons between SAS4A/SASSYS- 1 and CERES of the full-flow steady-state conditions show very good agreement for both protected and unprotected loss-of-flow transients. During pump coast-down periods at the beginning of each transient, temperatures and flow rates continue to show excellent agreement. However, beyond the initial parts of the transients, where natural circulation behavior begins to dominate, the results for temperature and flow begin to show differences.[6]

Thermal stratification in the outlet plenum has been identified as a potential contributor to the natural circulation flow discrepancies between the two codes. Figure 2 shows the impact of outlet plenum treatment on the intermediate heat exchanger (IHX) primary-side inlet temperature during a protected loss of flow accident.

When a simple mixing model is assumed (no stratification, bottom curve) the initially colder outlet temperature from the core lowers the average plenum temperature that is seen at the IHX inlet. On the other hand, when a simple, three-layer stratified model is used (top curve) the IHX is only exposed to the top, hot layer during the first hour of the transient. By comparison, the low-fidelity, two-dimensional plenum treatment computed by CERES shows an intermediate temperature profile.

Incorrect predictions of IHX primary inlet temperatures affect the predictions of natural circulation flow rates in the primary loop as well as heat rejection rates to the intermediate loop. This, in turn, impacts peak coolant and fuel temperatures observed during the transient. Between 1200 and 3600 seconds, the results for core outlet temperature show unacceptably large differences. In the PLOF comparison described above, peak core outlet temperatures following the scram differed by approximately $75^{\circ} \mathrm{C}$, with the higher prediction slightly above nominal outlet temperatures. Furthermore, the timing of the peak temperature differs by nearly 10 minutes. Differences in core outlet temperatures are shown in Figure 3.

In order to better predict the conditions of thermal stratification during this transient, a higher-fidelity treatment of the outlet plenum is required. To accomplish this, the whole-plant simulation capabilities of SAS4A/SASSYS-1 have been coupled to the computational fluid dynamics code STAR-CD.[7] STAR-CD is a commercial CFD code with a wide range of 
applications, including buoyancy driven flows and heat transfer. Its modeling capabilities include turbulence models based on the Reynolds Averaged Navier-Stokes (RANS) approach, temperature dependent thermophysical properties, unstructured mesh over arbitrarily-shaped boundaries, and a functionality to include user-developed code.

The capability to employ STAR-CD to improve the SAS4A/SASSYS-1 plenum model was initiated in FY09 and is detailed in Reference 8. In the previous effort, a standalone SAS4A/SASSYS-1 calculation was performed and the resulting predictions for the core channel outlet temperature and flow rates were exported. A STAR-CD model of the outlet plenum was also developed which used the exported data as boundary condition. This initial coupling was "one-way" or unidirectional coupling in that SAS4A/SASSYS-1 provided information to STAR-CD, but there was no feedback from STAR-CD to SAS4A/SASSYS-1. In this updated work, the STAR-CD prediction of the core and IHX inlet temperatures and pressures are provided back to the SAS4A/SASSYS-1 model of the primary coolant system. It is now possible to evaluate the influence of thermal stratification in the outlet plenum on the remainder of the primary system, including the effect on the temperatures in the core. Results of the analysis based on SAS4A/SASSYS-1/STAR-CD coupling are presented below.

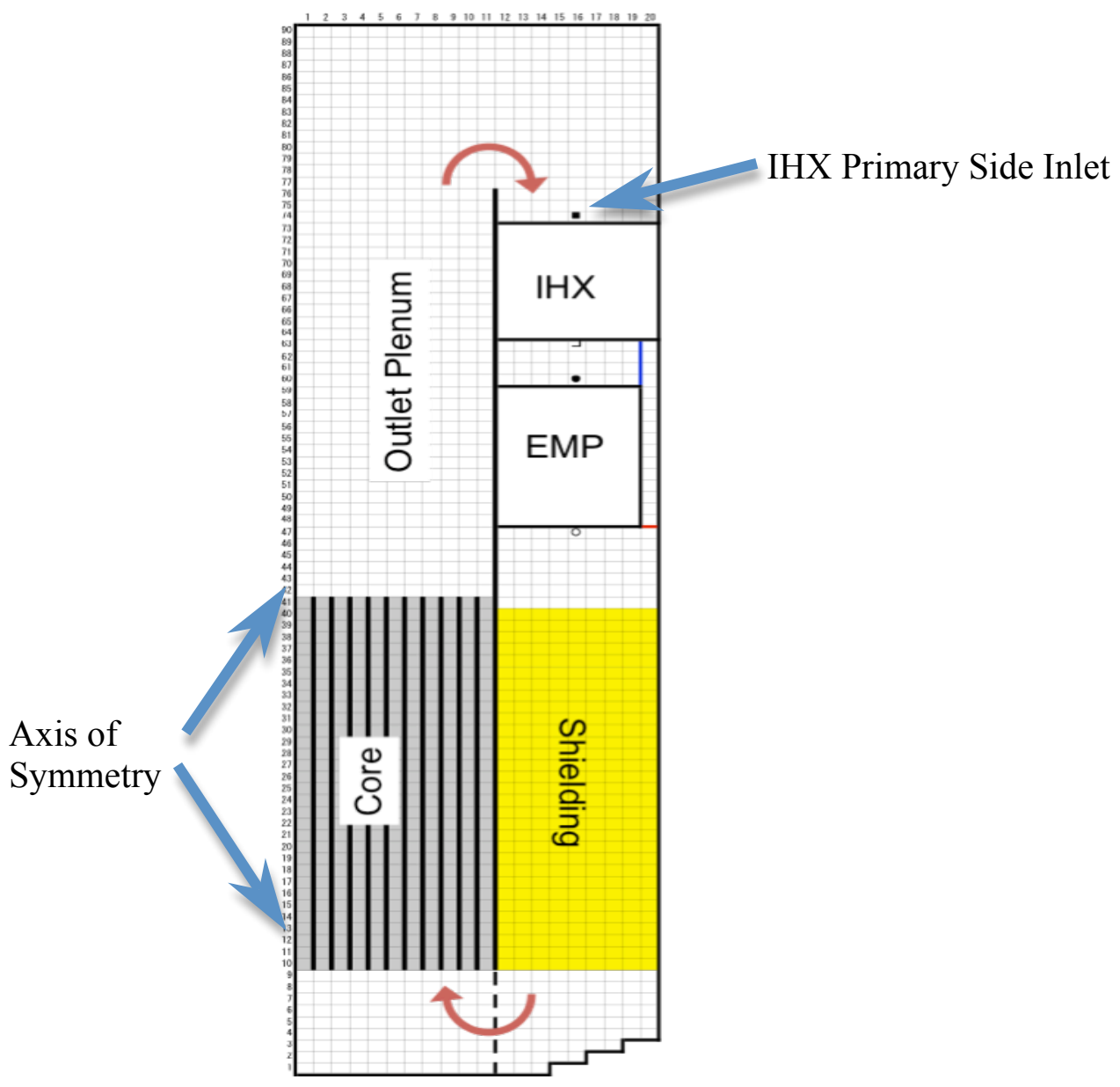

Figure 1: Simplified Representation of the 4S Primary System (not to scale). 


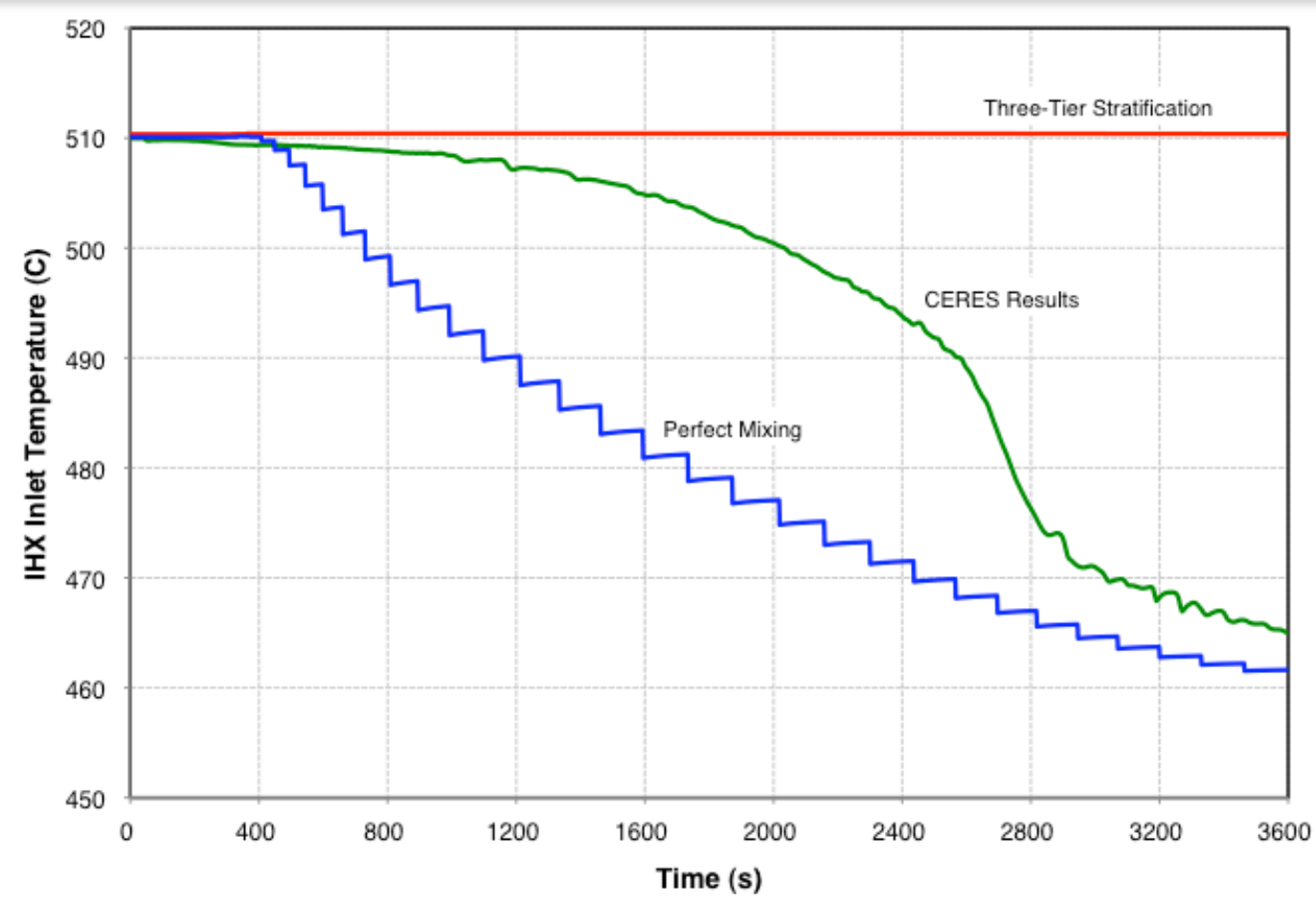

Figure 2: IHX Primary Inlet Temperatures With and Without Thermal Stratification in the SAS4A/SASSYS-1 Model Compared to the Results Predicted by CERES.

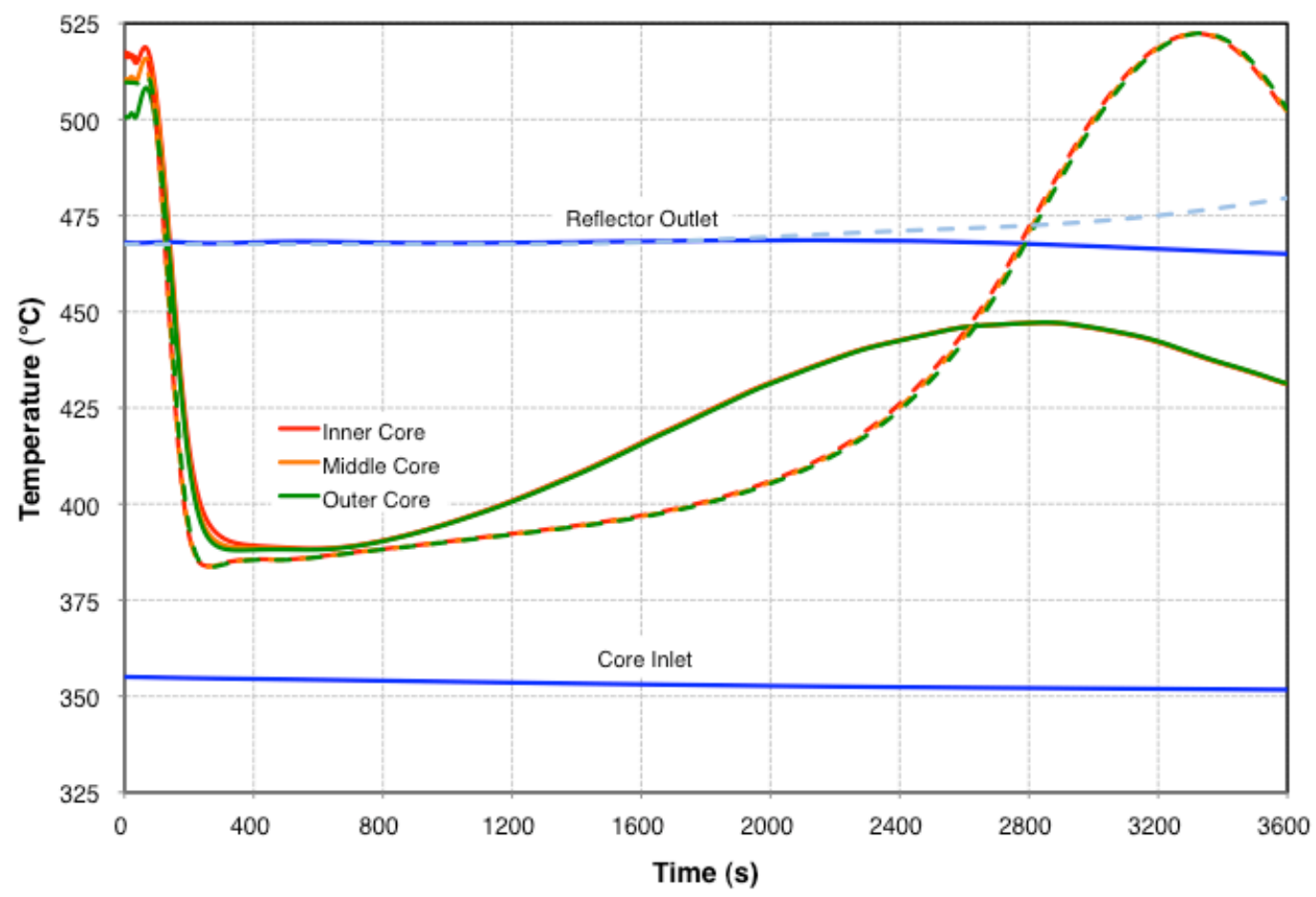

Figure 3: Comparison of Core Inlet and Outlet Coolant Temperatures between SAS4A/SASSYS-1 (Solid Lines, No Stratification) and CERES (Dashed Lines). 


\section{Coupling}

The PRIMAR-4 module of SAS4A/SASSYS-1 computes coolant pressures, flow rates, and temperatures in the primary and intermediate heat transport loops. Within a given time step during a transient, liquid flow rates and pressures are calculated first, taking into account changes in pressure and flow rates during the time step but ignoring temperature changes. Then, with liquid flow rates know, liquid temperatures are calculated. This separation takes advantage of the fact that single-phase liquid flow rates are more sensitive to pressure changes than temperature changes and provides an opportunity for coupling.

\subsection{Flow Rates}

Equations for hydraulic conditions in the primary and intermediate coolant loops are solved by a semi-implicit or fully implicit time differencing scheme in which pressures and flows for all connected compressible volumes and liquid flow segments are solved simultaneously. The equations are linearized, and can therefore be solved without resorting to iteration techniques. Linearized equations are also useful for long transients in which temperatures and flows change slowly.

In the PRIMAR-4 network model, three coupled equations are used to solve for pressure in the compressible volumes and for flow rates in the liquid segments. These include the momentum equation for incompressible single-phase flow in the liquid segments, an expression for the average flow in a liquid segment over a time step to account for changes in flow during the time step, and an expression for changes in compressible volume pressure as a result of flows into and out of the compressible volume. The coefficients to these equations are unique for each compressible volume and liquid flow element type. This allows a wide variety of system components to be modeled.

The momentum equation for single-phase incompressible liquid can be integrated over a liquid flow segment and summarized as

$$
\begin{aligned}
\frac{L}{A} \frac{d w}{d t} & =f(w, t) \\
& =p_{\text {in }}(w, t)-p_{\text {out }}(w, t) \\
& -\Delta p_{f r}(w, t)-\Delta p_{w^{2}}(w, t)-\Delta p_{v}(w, t)-\Delta p_{g r}(w, t)+\Delta p_{p}(w, t)
\end{aligned}
$$

where $w$ is the flow rate $(\mathrm{kg} / \mathrm{s}), L$ is the length of the flow segment and $A$ is the cross sectional area. Changes in flow are driven by the differences in inlet and outlet pressure balanced by friction, form, and valve pressure losses along with gravity and pump heads, respectively.

Inlet and outlet pressures for a liquid segment are determined by the properties and conditions of the compressible volumes connected at each end. Pressure in a compressible volume is assumed to vary linearly with changes in the mass or temperature of the liquid. Therefore, changes in the pressure of a compressible volume at a reference location can be written as

$$
\Delta p_{r}=B_{0}+B_{1}\left(\sum \bar{w}_{\text {in }}-\sum \bar{w}_{\text {out }}\right)+B_{2}\left(\sum \bar{w}_{\text {in }} T_{\text {in }}-\sum \bar{w}_{\text {out }} T_{\text {out }}\right)
$$


where $\bar{w}_{\text {in }}$ and $\bar{w}_{\text {out }}$ are the individual inlet and outlet flow rates of each connected segment averaged over the time step. The coefficients $B_{0}, B_{1}$, and $B_{2}$ are defined based on the properties of the compressible volume and include the effects of liquid compressibility, liquid and vessel wall thermal expansion, vessel expansion due to internal pressure, cover gas expansion or contraction, and external heat sources or sinks. Some of these effects are extremely difficult to represent with existing CFD tools. Because of this, reference pressure calculations in the coupled solution are solved by SAS4A/SASSYS-1, but two important temperature corrections are considered.

In a perfect mixing model, the temperature of any coolant flowing out of the compressible volume is simply the mixed mean temperature of the volume. In Equation (2), $T_{\text {out }}$ would be the same for all out-flowing connections. By eliminating the perfect mixing assumption and using a coupled CFD solution, however, $T_{\text {out }}$ is unique for each outlet connection and will likely be different than the mixed mean. By taking this into consideration, the energy balance within the compressible volume will be more accurately resolved and the change in pressure during the time step will be more accurately predicted.

The second temperature effect involves the calculation of $p_{\text {in }}$ and $p_{\text {out }}$ for Eq. (1). Under the assumptions of a perfect mixing model, the inlet pressure is calculated by

$$
p_{\text {in }}=p_{r}+\rho_{m m} g\left(z_{r}-z_{\text {in }}\right)
$$

where $\rho_{m m}$ is the density of the coolant at the compressible volume mixed mean temperature, $g$ is the acceleration due to gravity, $z_{r}$ is the elevation of the reference pressure location, and $z_{i n}$ is the elevation of the inlet. With the coupled CFD solution available, a more detailed temperature and density distribution is known. Therefore, the inlet pressure used in the momentum equation can be more accurately defined:

$$
p_{\text {in }}=p_{r}+g \int_{z_{i n}}^{z_{r}} \rho(T) d z
$$

In practice, the CFD solution calculates both the static head due to gravity and the dynamic pressure drop due to flow. For large volumes such as reactor outlet plenums, dynamic pressure is negligible compared to static pressure. Nevertheless, both contributions are included, and the inlet pressure for the coupled solution is calculated as

$$
p_{\text {in }}=p_{r}+\Delta p_{\mathrm{CFD}}
$$

where $\Delta p_{\mathrm{CFD}}$ is the pressure difference in three-dimensional space calculated by CFD between the inlet and the reference locations. A similar treatment is used for outlet connections.

With the above modifications, liquid flow rates and reference pressures for all connected compressible volumes and liquid flow segments are solved simultaneously. Once updated flow rates are known, the CFD calculation updates the flow and temperature distributions within each compressible volume for which a high-fidelity treatment option has been selected.

\subsection{Temperatures}

In the previous section, the improvements made to the flow rate calculations as a result of a higher-fidelity plenum treatment were described. Once flow rates and pressures are 
determined, liquid temperatures are determined. For compressible volumes that are treated by a high-fidelity CFD model, detailed temperature distributions are calculated based on the incoming and outgoing flows connected to the volume. SAS4A/SASSYS-1 still calculates the mixed-mean average based on the simple perfect mixing model, which can be compared to the CFD results for verification.

SAS4A/SASSYS-1 supports liquid flow segments that contain arbitrary combinations of elements, including pipes, bypass channels, intermediate heat exchangers, steam generators, pumps, valves, and annular pipes. For temperature calculations, the elements in a liquid segment are combined into temperature groups that are solved simultaneously.

A Lagrangian approach is typically used for temperature calculations, where coolant node boundaries move with the flow and exchange heat with the walls of the flow element. The time-step sub-interval over which temperatures are evaluated is limited so that coolant cannot move more than one node per time step. When a liquid segment inlet is connected to a compressible volume that is represented with a CFD model, the data exchange between CFD and SAS4A/SASSYS-1 is synchronized to the sub-interval time step. Therefore, inlet temperatures used in the liquid segment temperature calculations are always up to date.

For the inlet node of a liquid segment, coolant is added to the node until its volume matches that of the other nodes in the temperature group. At that point, the node detaches from the inlet and a new inlet node is formed. The heat transfer equation for the inlet node has the following form:

$$
C \frac{\partial}{\partial t}\left[f T_{c}\right]=C \bar{T}_{i n} \frac{\partial f}{\partial t}+W f\left(T_{w}-T_{c}\right)
$$

where $T_{c}$ and $T_{w}$ are the coolant and wall temperatures of the inlet node and $\bar{T}_{\text {in }}$ is the temperature of the coolant entering the element from the compressible volume. The coefficients $C$ and $W$ represent coolant and wall node properties and account for density, heat capacity, flow area, and heat transfer coefficient and surface area. The variable $f$ represents the fractional size of the inlet node and is in the range $0<f \leq 1$.

Without a CFD plenum treatment, the liquid segment inlet temperature, $\bar{T}_{i n}$, is defined by the mixed-mean compressible volume temperature, which would be the same for all outlet connections. With a coupled CFD plenum model, $\bar{T}_{\text {in }}$ is unique for each liquid segment and corresponds to $T_{\text {out }}$ in Equation (2). That is, each outlet from a compressible volume supplies coolant to the inlet of the corresponding liquid segment.

This apparently simple change can have a dramatic impact on whole-plant simulations. As shown in the results section below, changes to the IHX inlet temperature affects the cold leg of the primary system and, in turn, the natural circulation flow rates that develop during a loss-of-flow transient and heat rejection rates to the intermediate system. Thermal stratification in the outlet plenum is responsible for the changes to the IHX inlet temperatures, and a perfect mixing model is unable to characterize the stratified temperature distributions.

\subsection{Time Synchronization}

The exchange of data between SAS4A/SASSYS-1 and a CFD calculation takes place at every PRIMAR-4 subinterval, therefore the two codes require proper timing synchronization. 
SAS4A/SASSYS-1 employs a multilevel adaptive time step approach that resolves power and reactivity, heat transfer, core flow, and whole system responses at appropriate scales. All time steps synchronize on the "main" time step.

The main, PRIMAR-4, and CFD time step relationships are shown in Figure 4. Typically, CFD time steps are the smallest in order to resolve high-fidelity flow and temperature fields within a compressible volume. In terms of the rest of the primary and intermediate system, the large volumes being represented usually have much slower response times, and the corresponding PRIMAR-4 time steps are longer.

Synchronization between SAS4A/SASSYS-1 and a CFD code is maintained through a file-locking mechanism. For example, when computing a subinterval, SAS4A/SASSYS-1 first acquires a file lock. It then passes flow and temperature, along with the gradients of flow and temperature, as boundary condition data to the CFD solver for each of the liquid segments connected to the compressible volume. Possession of the file lock also passes to the CFD solver.

Once the CFD solver has determined the flow and temperature distributions for the compressible volume at the end of the PRIMAR-4 subinterval, it acquires its own file lock. It then passes pressure and temperature data for Equations (1) and (2) back to SAS4A/SASSYS1. Possession of the newly acquired file lock also passes to SAS4A/SASSYS-1, at which point the CFD solver releases the file lock it obtained at the beginning of the subinterval. Release of this lock indicates it has completed the subinterval, and control passes back to SAS4A/SASSYS-1.

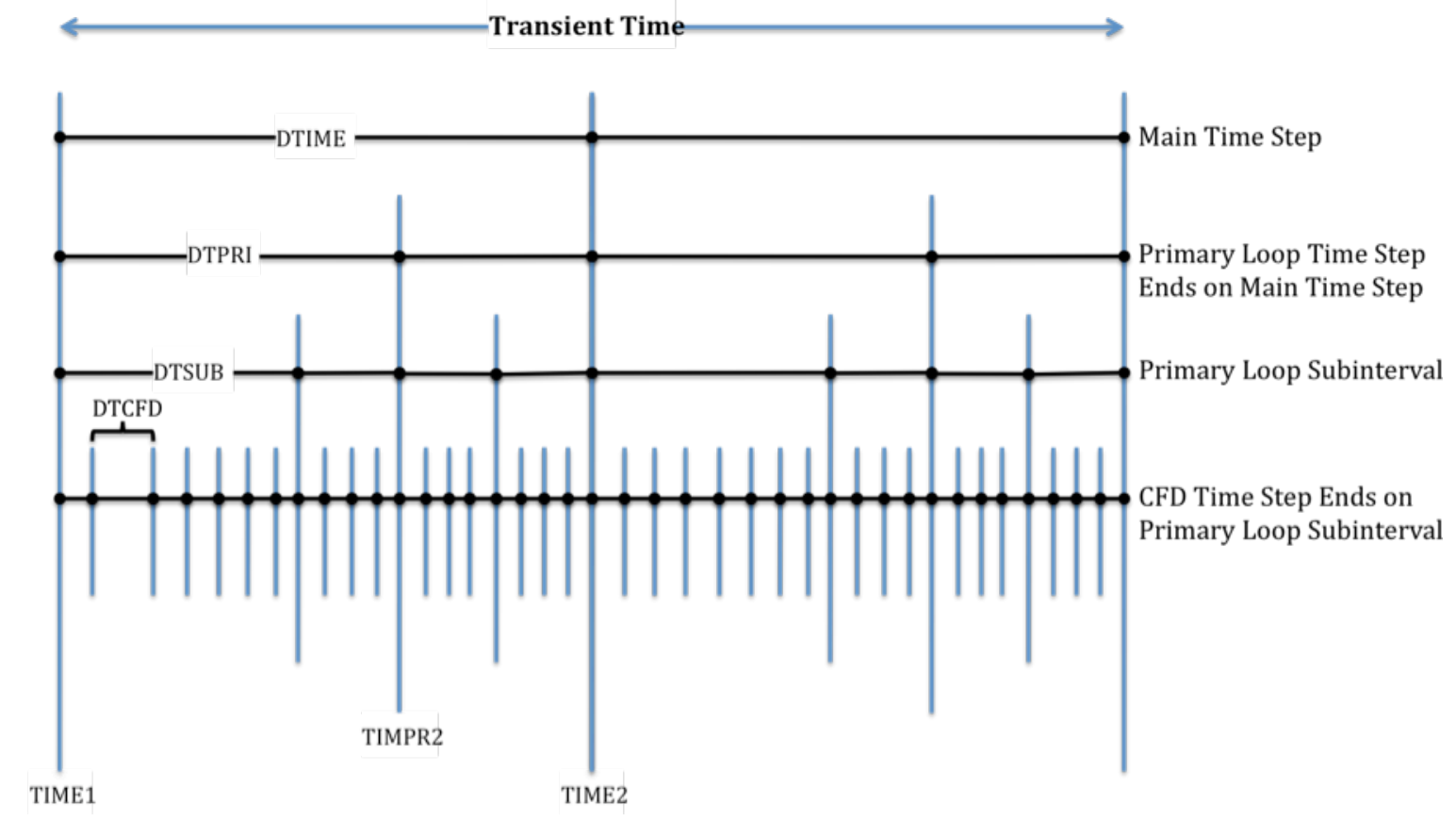

Figure 4: Time Step Hierarchy between Modules in SAS4A/SASSYS-1 and CFD 
Initialization of the synchronization at the beginning of a simulation is slightly more complicated because both codes must first process input, initialize data structures, and prepare a steady-state solution. Much of this occurs asynchronously. Nevertheless, a similar filelocking mechanism is used to indicate when both solvers are ready to proceed with the simulation. When that occurs, SAS4A/SASSYS-1 takes control and provides steady-state boundary conditions to the CFD solver. The option of beginning with a "null transient" is also supported so that both codes will converge to the same initial conditions. Both null transient and standard transient calculations then proceed according to the synchronization method described above.

\subsection{CFD Implementation}

In order to couple with SAS4A/SASSYS-1, a CFD solver must be able to send and receive boundary condition data and synchronize its time steps within a multi-processor framework for distributed memory parallelization. For this work, the commercial CFD code STAR-CD was used.[7] Customization of STAR-CD is implemented via so-called user subroutines which access an application-programming interface to modify the normal runtime behavior of the STAR-CD code.

Each boundary surface (e.g. the IHX inlet or core channel outlet) in STAR-CD is discretized into arbitrarily many cells. Thus, it is necessary to perform a mass average from all contributing cells along the boundary surface when computing the temperature and pressure for SAS4A/SASSYS-1. With STAR-CD, these averages are computed using the cell-centered values of the cells immediately adjacent to the boundary. The exact boundary data is not available in the user subroutines, so this will introduce some small error in the coupling, which may be considered an additional $O(\Delta x)$ truncation error.

Typically, the time step size required by CFD is smaller than that required by the SAS4A/SASSYS-1 code. STAR-CD employs an implicit time step scheme, so the time step size is limited by accuracy rather than stability. SAS4A/SASSYS-1 provides the beginning and end time for a subinterval to STAR-CD. STAR-CD then iterates using a default usersupplied time step size (e.g. 0.05 seconds in the 4S model) and interpolates the SAS4A/SASSYS-1 temperature and flow data to evaluate boundary conditions for intermediate time steps. On the final STAR-CD time step within the larger subinterval, it may be necessary to adjust the STAR-CD time step size in order to synchronize.

The CFD simulations presented here were performed utilizing all four cores of single node on a Linux cluster. Because such a simulation does not require network communication, this permits good scalability for a small CFD model. In the STAR-CD parallel implementation, most I/O operations are performed on the local hard disk of the machine, and only the root process has access to the user file system. Thus, the root process is responsible for all communication with SAS4A/SASSYS-1 through the file-locking mechanism described above. The root process must then broadcast data read from SAS4A/SASSYS-1 to all other processes using MPI functions, which would require network communication for larger multinode simulations. Conversely, in order to calculate the pressure and temperature at the boundaries for SAS4A/SASSYS-1, contributions from each process must be collected on the root via an MPI reduction operation. This implementation has the advantage of simplifying the procedure for synchronizing with SAS4A/SASSYS-1 and is consistent with the internal $\mathrm{I} / \mathrm{O}$ procedure in STAR-CD. The additional overhead required to perform the MPI broadcast 
and reduction operations are trivial: 5 words per STAR-CD boundary surface need to be broadcast and 3 words per boundary surface need to be reduced. For the current $4 \mathrm{~S}$ model, only 320 bytes of data are needed. Even if each channel and IHX inlet of a large SFR were represented explicitly, this communication overhead would still be tiny compared to the total communication expense for the CFD simulation.

Certain SAS4A/SASSYS-1 model data must be supplied to the CFD coupling implementation. The user subroutines must be aware of the desired time step size and the number of inlet and outlet boundaries in the SAS4A/SASSYS-1 model and how they map to STAR-CD inlet and outlet boundaries. In the current implementation, this data is hard-coded in a Fortran 90 module that is linked with the STAR-CD user subroutines. This may seem somewhat unwieldy, but it is important to keep in mind that the CFD model must always be developed for the precise purpose of coupling with SAS4A/SASSYS- 1 and not developed independently treating SAS4A/SASSYS-1 as a "black box". A production tool may implement something more elegant such as a text input file or even a graphical user interface, but the CFD modeler must have knowledge of the primary coolant systems model in SAS4A/SASSYS-1.

\section{Coupled Model Description}

Analysis of the protected loss-of-flow (PLOF) accident sequence for the 4S was performed with the coupled heat transfer, thermal-hydraulics, and reactor kinetics models available in the SAS4A/SASSYS- 1 code. The PLOF accident begins with a loss of normal power to the primary, secondary, and feedwater coolant pumps due to a loss of the internal power supply (station blackout). This results in an immediate loss of forced flow in the primary and secondary coolant circuits. Equipment that provides a programmed flow coast down of the primary reactor coolant pumps is assumed to operate, and the flow coast down of the primary pump is assumed to follow a 15 second initial halving time. Secondary pump flow is assumed to stop immediately. When primary pump power reaches $80 \%$, a reactor scram interlock signal will occur, and the reactor will scram following a short delay to account for response time.

Adiabatic conditions are assumed at the steam generator due to the water supply pump trip. As a result, the only heat removal during the transient is through the reactor vessel auxiliary cooling system (RVACS) and the intermediate reactor auxiliary cooling system (IRACS).

In the PLOF sequence, the absence of normal shutdown heat removal through the reactor coolant system causes a slow system temperature rise following the reactor scram. This temperature increase occurs because the RVACS and IRACS have insufficient heat removal capacity to overcome both the early decay heat production rate and the stored heat in the primary and secondary systems. Eventually, the decay heat will fall below the emergency cooling capacity, and the system temperature will decline.

Analysis of the PLOF accident sequence was performed at end of cycle conditions, which corresponds to a core lifetime of 30 years. The initial power and flow were 1.8 and $2.0 \%$ higher than nominal conditions for the $4 \mathrm{~S}$ design under consideration. Total reactor power at the start of the PLOF accident is $30.55 \mathrm{MW}$ and total primary coolant flow is $155 \mathrm{~kg} / \mathrm{s}$. Decay heat is taken as $120 \%$ of the ANSI 5.1 standard[9] for U-235 fission after a steady-state 
irradiation time of 30 years. Although nominal values for reactivity feedback parameters are used, a programmed scram reactivity of approximately -15 dollars dominates the net reactivity calculation.

\subsection{Primary and Secondary System Modeling}

In the SAS4A/SASSYS- 1 code the PRIMAR-4 module treats the primary and secondary sodium loops, as well as the steam generator. A schematic of the model used in PRIMAR-4 for this work is shown in Figure 5. This figure is not to scale. The flow elements used in this model are described in Table I, and the compressible volumes are described in Table II.

The modeling of the outlet plenum is somewhat complex. CV2 represents the main part of the outlet plenum, while E2 is an annular pipe element representing the part of the outlet plenum over the IHX and between the redan and the vessel wall. PRIMAR-4 contains two options that can be used in CV2 for the outlet plenum: a perfect mixing model and a simple onedimensional thermal stratification model. For the coupled calculations, the perfect mixing model was used in CV2.

For the pumps, an EM pump model was used in PRIMAR-4. PRIMAR-4 adds the pump head to the natural circulation head when calculating flow rates. The input for the primary pump was adjusted so that it would give a flow proportional to $1 /(1+t / 15)$, where the time $t$ is in seconds, if there were no gravity head. The primary pump head is set to zero after 800 seconds. The actual flow calculated for the transients depends both on this pump head and on the calculated natural circulation head. The secondary pump head was set to zero one second after the pump tripped.

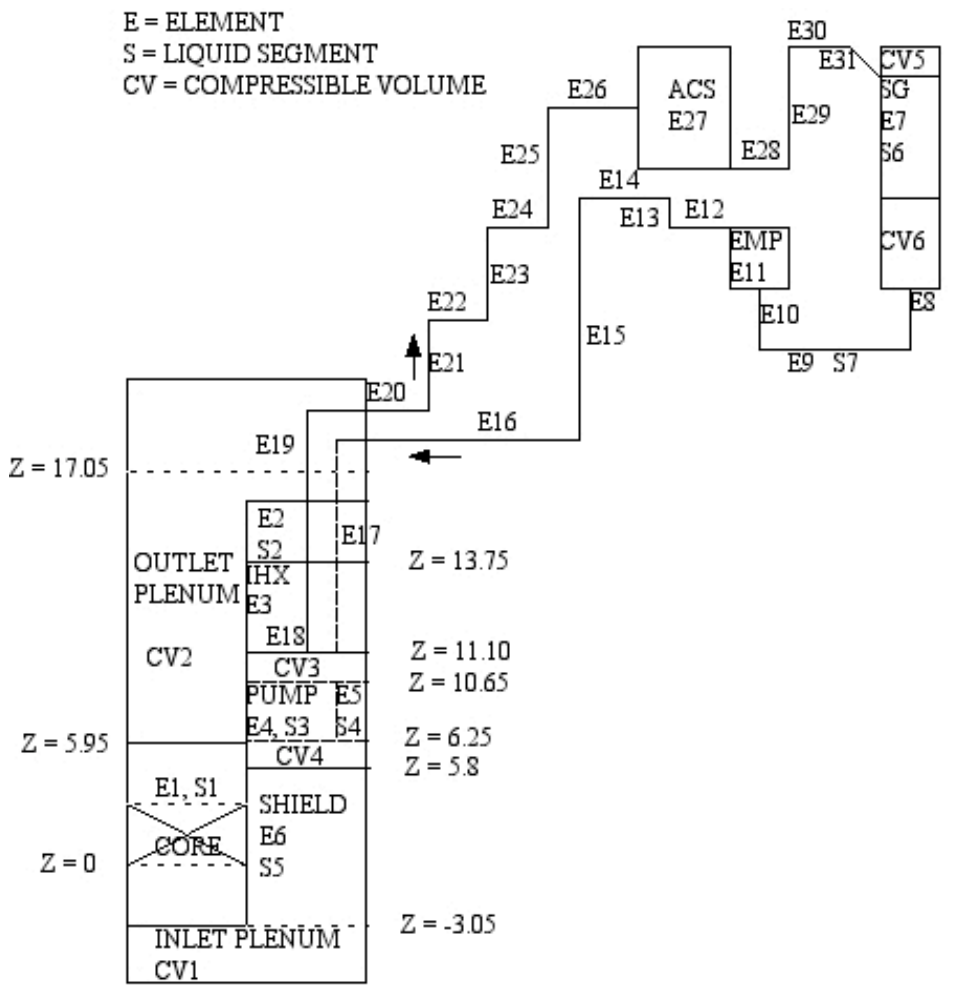

Figure 5: PRIMAR-4 Network Model for the 4S Reactor. 
Table I: Flow Elements Used in the PRIMAR-4 Model for the 4S.

\begin{tabular}{|c|c|c|}
\hline Element & Type & Usage \\
\hline 1 & Core & Core Subassemblies \\
\hline 2 & Annulus & Part of Outlet Plenum \\
\hline 3 & IHX Tube Side & IHX Primary \\
\hline 4 & Pump & Primary EM Pump \\
\hline 5 & Annulus & Cooling Annulus between Pump and RV \\
\hline 6 & Annulus & Shielding \\
\hline 7 & Steam Generator & Simple Steam Generator Model \\
\hline 8 & Pipe & Lower plenum in the Steam Generator \\
\hline 9 & Pipe & Secondary Piping \\
\hline 10 & Pipe & Secondary Piping \\
\hline 11 & Pump & Secondary EM Pump \\
\hline 12 & Pipe & Secondary Piping \\
\hline 13 & Pipe & Secondary Piping \\
\hline 14 & Pipe & Secondary Piping \\
\hline 15 & Pipe & Secondary Piping \\
\hline 16 & Pipe & Secondary Piping \\
\hline 17 & Pipe & Secondary Piping and IHX Downcomer \\
\hline 18 & IHX Shell Side & IHX Secondary \\
\hline 19 & Pipe & Secondary Piping \\
\hline 20 & Pipe & Secondary Piping \\
\hline 21 & Pipe & Secondary Piping \\
\hline 22 & Pipe & Secondary Piping \\
\hline 23 & Pipe & Secondary Piping \\
\hline 24 & Pipe & Secondary Piping \\
\hline 25 & Pipe & Secondary Piping \\
\hline 26 & Pipe & Secondary Piping \\
\hline 27 & Air Dump Heat Exchanger & ACS \\
\hline 28 & Pipe & Secondary Piping \\
\hline 29 & Pipe & Secondary Piping \\
\hline 30 & Pipe & Secondary Piping \\
\hline 31 & Pipe & Secondary Piping, SG Inlet \\
\hline
\end{tabular}


Table II: Compressible Volumes Used in the PRIMAR4 Model for the 4S.

\begin{tabular}{cl}
\hline Volume & Usage \\
\hline 1 & Inlet plenum \\
$\mathbf{2}$ & Outlet plenum with cover gas \\
3 & Plenum between IHX and Pump \\
4 & Plenum between pump and shield \\
5 & Cover gas and upper sodium in the steam \\
& generator \\
6 & Lower sodium in the steam generator \\
\hline
\end{tabular}

\subsection{Outlet Plenum Geometry}

The outlet plenum of the $4 \mathrm{~S}$ is approximately eleven meters tall. A simplified threedimensional surface representation of the outlet plenum is shown in Figure 6. From the core outlet elevation (red surface) to the IHX inlet elevation (green surface) is approximately 7.7 meters. There is a 0.58 meter annular wall that extends above the elevation of the IHX, so coolant must first travel vertically at least 8.3 meters before dropping into the IHX inlet.

SAS4A/SASSYS-1 can approximate the outlet plenum by a compressible volume with a perfect mixing model. During higher flow conditions, this treatment may be adequate and comparisons between SAS4A/SASSYS-1 and CERES have shown good agreement during the initial part of the PLOF transient. At later times, however, significant differences occur due to the inability of the simplified SAS4A/SASSYS-1 compressible volume model to treat the low-flow thermal stratification that occurs.

To improve comparisons, an annular flow element was added to the PRIMAR-4 model of SAS4A/SASSYS-1 to represent the distinct region above the IHX. This is shown as Element 2 (E2) in Figure 5 and in Table I. Although this extends the duration of the agreement between the two codes to just beyond 400 seconds (see Figure 2 above), the physical explanation between the two is different. In the case of CERES, the delay is due to thermal stratification in the plenum, which extends well beyond 400 seconds. In SAS4A/SASSYS-1, the delay in the drop in the IHX inlet temperature is due to the long transit time of sodium through the annular element during low flow conditions. This effect should be regarded as artificial since it is the result of a Lagrangian slug flow treatment. Therefore, more accurate representations are required through the use of higher-fidelity methods applied to the outlet plenum.

In the coupled calculations presented in this report, the annular element described above was made very small $(12 \mathrm{~cm})$ to effectively eliminate it from the model. Therefore, the SAS4A/SASSYS-1 uncoupled results using the perfect mixing model show an even more rapid drop in the IHX temperature than shown in previous results. This more clearly highlights the limitations of the perfect mixing model used in compressible volumes, while at the same time eliminating an "ad hoc" model change needed to partially overcome this limitation. 


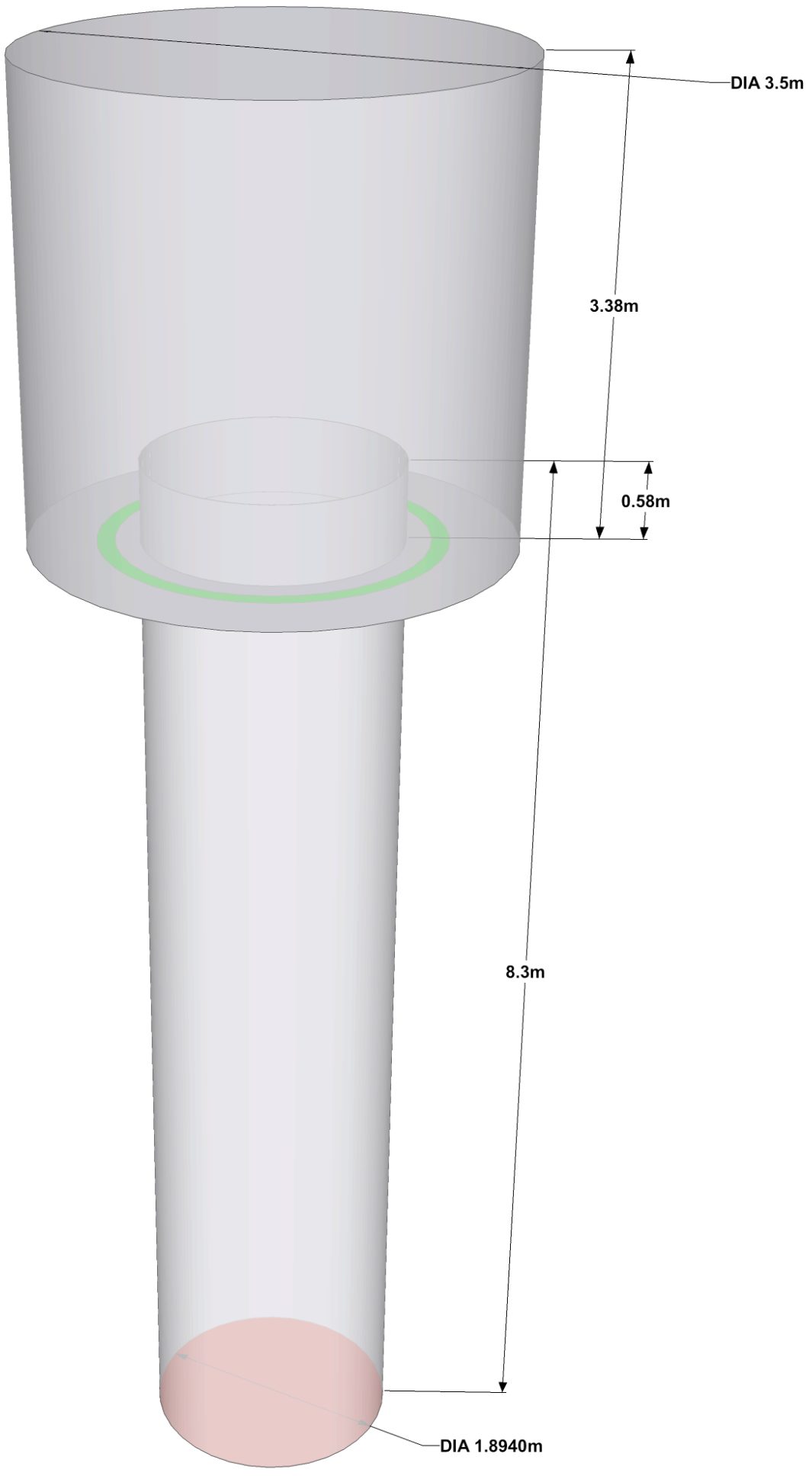

Figure 6: Three-dimensional surface representation of the $4 \mathrm{~S}$ outlet plenum. The red surface represents the core outlet/plenum inlet while the green surface represents the plenum outlet/IHX inlet. Details of the core outlet are excluded, but include separate regions for each subassembly outlet. 


\subsection{CFD Model}

The STAR-CD model employed for the SAS4A/SASSYS-1 coupling demonstration is identical to the two-dimensional, single-phase, axisymmetric model described in the previous report on the coupling effort.[8] The conclusion from this previous work was that the results from this simple, faster-running model were nearly identical to the more sophisticated models tested. Thus, it provides a good starting point for the development of more sophisticated coupling techniques with SAS4A/SASSYS-1. The only modification to the model in the previous reference is that the coefficients in the function for the temperature dependence of specific heat were modified, correcting a previous error in the implementation. The geometry of the axisymmetric model is shown in Figure 7. The grid contains 29,000 cells. The temperature dependence of sodium thermophysical properties is evaluated using the same expressions in SAS4A/SASSYS-1, and are implemented via user subroutines.

Because of the axisymmetric nature of the CFD model compared to the actual threedimensional conceptual design, it is not possible to directly map the SAS4A/SASSYS-1 channels to STAR-CD inlet boundaries. For instance, all middle and outer core channels appear in the same annular ring of the core, so there is no way to distinguish between them in an axisymetric model. It is therefore necessary to map the SAS4A/SASSYS-1 channels to appropriate boundary regions as detailed in Table III.

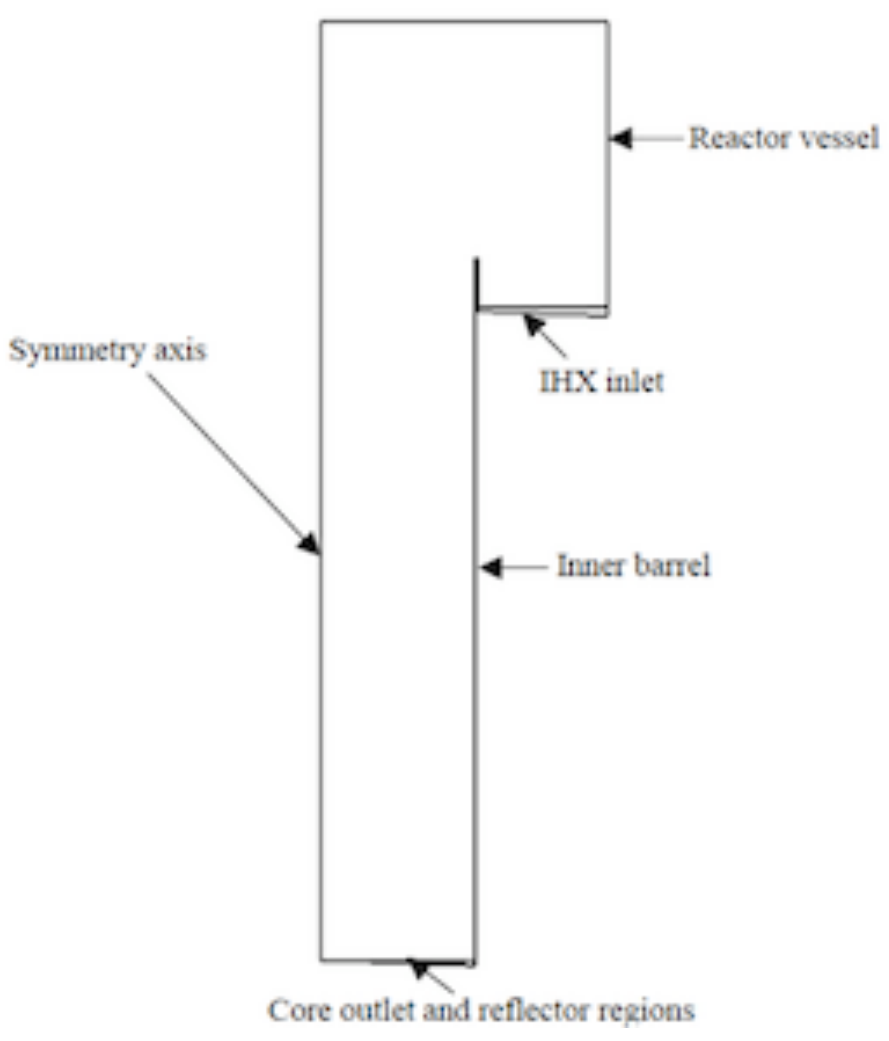

Figure 7: Geometry for Axisymmetric STAR-CD Model of the 4S Plenum 
Table III: Mapping of SAS4A/SASSYS-1 Channels to STAR-CD Inlet Regions in the Axisymmetric Model

\begin{tabular}{ccl}
\hline $\begin{array}{c}\text { SAS4A/SASSYS-1 } \\
\text { Channel }\end{array}$ & $\begin{array}{c}\text { STAR-CD } \\
\text { Boundary Region }\end{array}$ & Description \\
\hline 1 & 3 & Central Shut Down Rod \\
2 & 4 & Inner Core \\
3 & 4 & Inner Core \\
4 & 5 & Middle Core \\
5 & 5 & Outer Core \\
6 & 5 & Outer Core \\
7 & 5 & Outer Core \\
8 & 6 & Reflector \\
\hline
\end{tabular}

To facilitate the development of the coupled SAS4A/SASSYS-1 capability, the time step size was increased from 0.01 seconds in the previous work to 0.05 seconds. In order to evaluate the impact of this on the solution, sensitivity analyses were performed with STAR$\mathrm{CD}$ running in standalone mode. For these sensitivity analyses, the boundary condition for the core channel outlets was taken from earlier SAS4A/SASSYS-1 analyses reported in [8]. The evolution of the IHX inlet temperature from the sensitivity analysis is plotted in Figure 8. From this analysis, it appears that there is no appreciable difference between the results for the various time step sizes and thus the larger 0.05 second time step size is permissible.

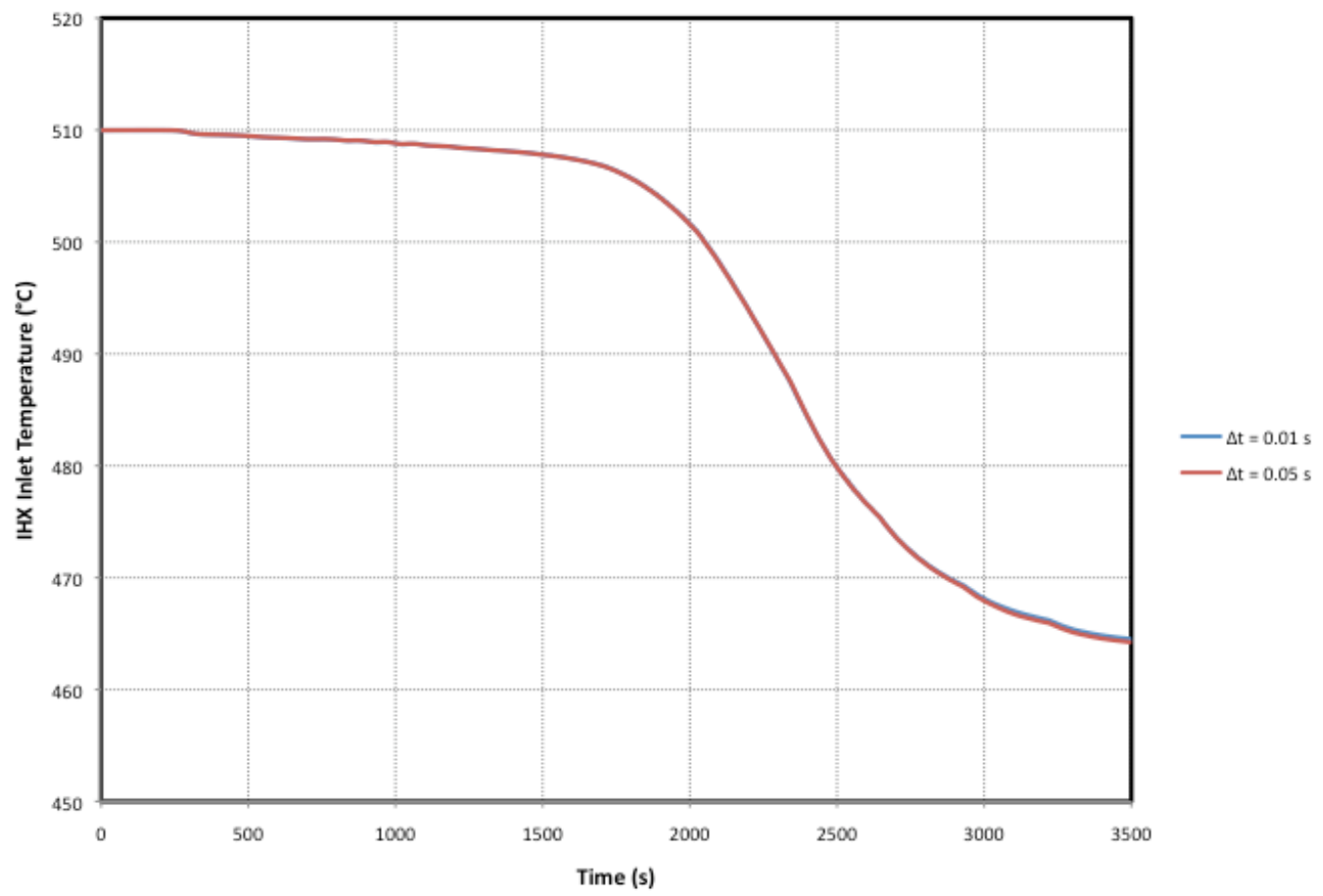

Figure 8: STAR-CD Time Step Size Sensitivity Study Results 


\section{Coupled Model Results}

Systems analyses of the protected loss-of-flow (PLOF) accident sequence were performed using the coupled heat transfer, thermal-hydraulics, and reactor kinetics models available in the SAS4A/SASSYS-1 safety analysis code and the high-fidelity CFD capabilities of the STAR-CD code. The results in this section compare two simulations. In one case, a "oneway" coupling was carried out in which data was sent from SAS4A/SASSYS-1 to STAR-CD, but data returned to SAS4A/SASSYS-1 was not used in the whole-plant simulation. In this case, the SAS4A/SASSY-1 results are identical to an uncoupled calculation, and the STAR$\mathrm{CD}$ results are based on corresponding boundary conditions. This is similar to the initial coupling analysis reported in [8]. For the coupled results that include a high-fidelity treatment of the outlet plenum, temperature, pressure, and flow coupling is carried out as describe above.

Coupled simulations were performed on a quad-core machine and required approximately 39 hours of wall clock time. Nearly all of the computational burden is associated with the CFD simulation of the plenum. The long run time is primarily associated with the long length of the transient; the 4200 seconds ( 800 second null transient and 3600 second transient) required 84,000 CFD time steps. Some of the computational burden may be alleviated by employing workstation machines with more cores - avoiding network communication while still reducing the size of the computational domain - or by improving the temporal discretization. While this is a rather expensive computation for design purposes by current standards, it is feasible with available computing resources at Argonne.

In the following sections, results from the SAS4A/SASSYS-1 systems models and the coupled SAS4A/SASSYS-1/STAR-CD models are presented. Because the results are based on a conceptual design, validation of the system performance cannot be carried out. Of particular interest, however, is the impact that high-fidelity treatment of a particular phenomenon can have on whole-plant performance.

\subsection{Steady-State Initialization}

In the PLOF accident sequence, the powers and flows were assumed to be 1.8 and $2.0 \%$ higher than nominal. Steady-state conditions for the PLOF case are shown in Table IV. In addition to core outlet temperatures, IHX primary- and secondary-side inlet and outlet temperatures are included. Under steady state, nominal flow conditions, the outlet plenum is well mixed, and the IHX primary-side inlet temperature is equal to the average core outlet temperature $\left(510^{\circ} \mathrm{C}\right)$. Heat losses from the outlet plenum are neglected.

The steady-state solution for the single-phase CFD model is achieved in two stages. In the first stage, steady-state calculations are run to force the solver to achieve a time-averaged flow field and temperature distribution. In the second stage, a time-dependent null transient is computed with fixed boundary conditions for an additional 25 minutes of simulation time to allow the solution to settle into one of its common modes of fluctuations typically observed in mixed convection flow regimes.

The CFD predictions for the initial condition of the plenum exhibit the expected behavior. Temperature distributions for the one-way and fully coupled results are shown in Figure 9. Heat is transferred quickly from the core plume to the region above the reflectors, yielding a fairly short thermal entrance region. The velocity magnitudes plotted in Figure 10 show that 
Table IV: Initial Steady-State Conditions for the Protected Loss-of-Flow Accident

\begin{tabular}{ll}
\hline & SASSYS-1 \\
\hline Core Power $(\mathrm{MW})$ & 30.549 \\
Primary Flow $(\mathrm{kg} / \mathrm{s})$ & 154.83 \\
Outlet Temperature, $\left({ }^{\circ} \mathrm{C}\right)$ & \\
Channel 1, Central Rod & 515.43 \\
Channel 2, IC & 516.35 \\
Channel 3, IC & 516.94 \\
Channel 4, MC & 510.42 \\
Channel 5, OC & 509.87 \\
Channel 6, OC & 500.49 \\
Channel 7, OC & 496.74 \\
Channel 8, Reflector & 467.98 \\
Core Inlet Temperature, $\left({ }^{\circ} \mathrm{C}\right)$ & 355.0 \\
Secondary Flow $(\mathrm{kg} / \mathrm{s})$ & 136.6 \\
RVACS Heat Removal $(\mathrm{MW})$ & 0.0886 \\
IHX Primary Inlet Temperature $\left({ }^{\circ} \mathrm{C}\right)$ & 510.45 \\
IHX Primary Outlet Temperature $(\mathrm{C})$ & 355.45 \\
IHX Secondary Inlet Temperature $(\mathrm{C})$ & 311.05 \\
IHX Secondary Outlet Temperature $(\mathrm{C})$ & 485.91 \\
\hline
\end{tabular}

above the reflector region near the plenum walls, the flow rate is quite small, and the core plume moves towards the interior of the plenum. As expected, pressure (Figure 11) varies quite linearly with elevation, as gravity head is dominant and dynamic pressure is negligible.

\subsection{Transient Results}

\subsubsection{Outlet Plenum Temperature Distributions}

The STAR-CD predictions for the outlet plenum temperature distribution for selected time steps are shown in Figure 12. At 2000 seconds, the difference between the one-way coupling and fully coupled results is substantial enough to be seen in the contour plots. From the SAS4A/SASSYS-1 results, the deviation exceeds $10^{\circ} \mathrm{C}$ (the increment in the contour plots) at approximately 1500 seconds. The vicinity of the IHX inlet appears cooler throughout the transient in the fully coupled case. In both cases, however, the temperature is much higher than in the perfect mixing model. 

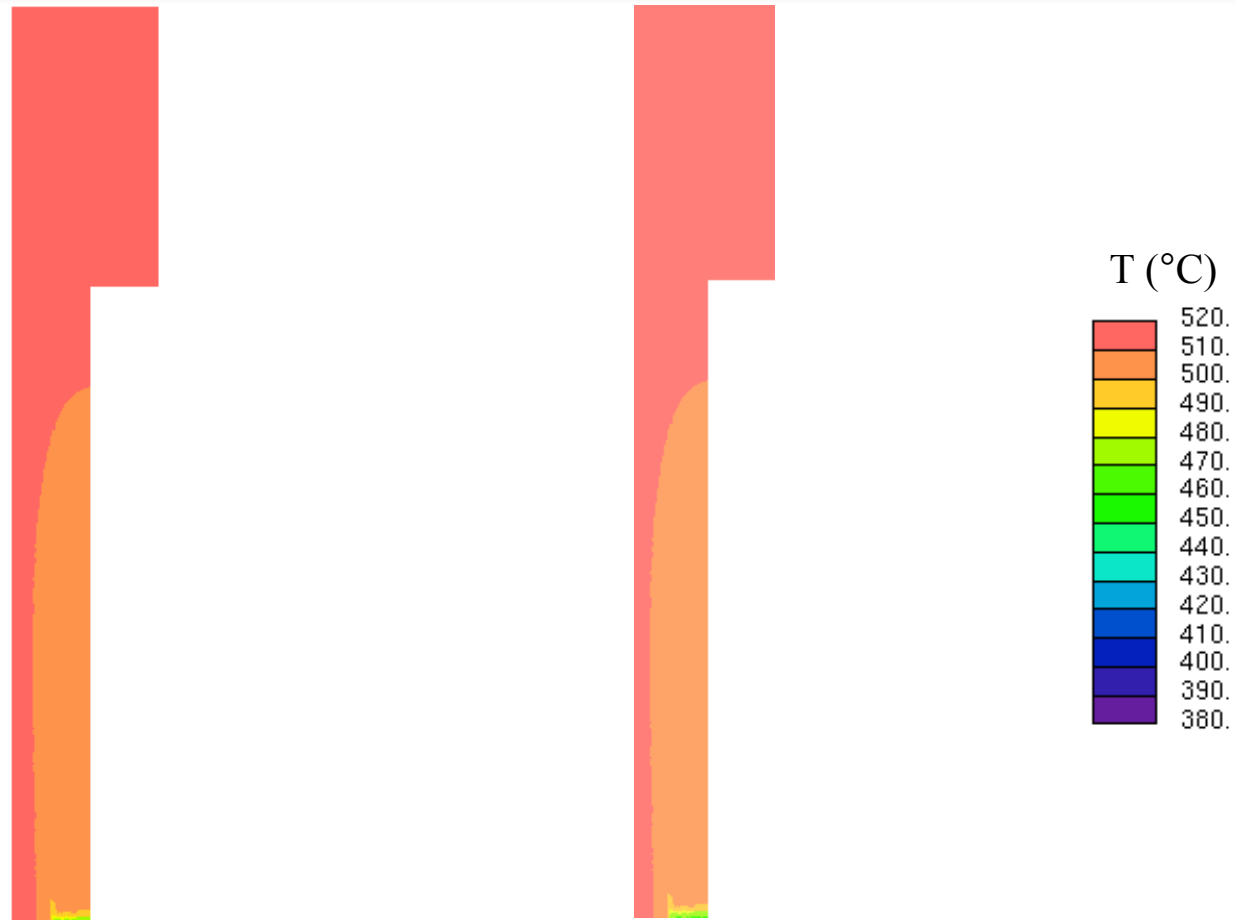

(a) One Way Coupling (b) Fully Coupled

Figure 9: STAR-CD Predictions for Temperature at $t=0$.

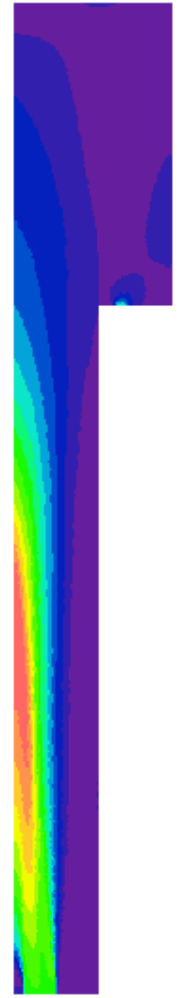

(c) One Way Coupling

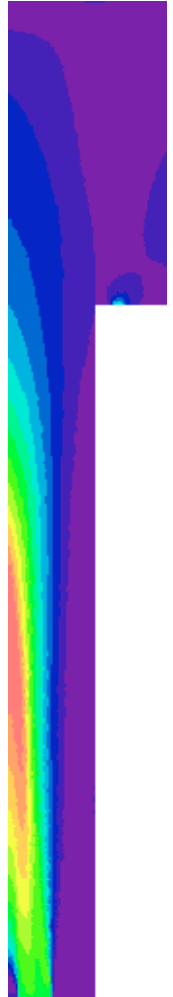

(d) Fully Coupled $|\mathbf{v}|(\mathrm{m} / \mathrm{s})$

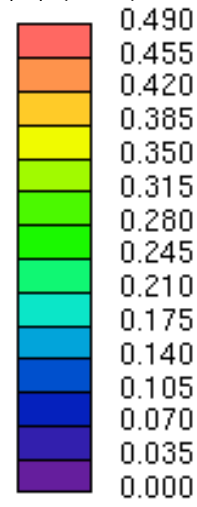

Figure 10: STAR-CD Predictions for Velocity Magnitude at $t=0$. 


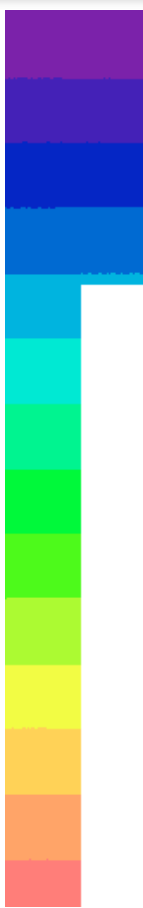

(b) Fully Coupled

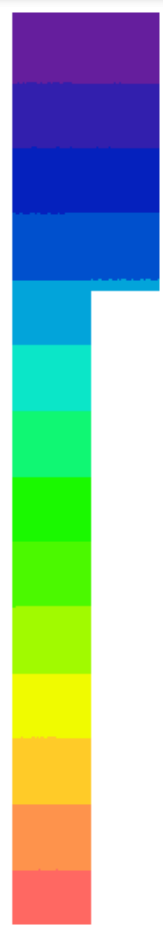

(a) One Way Coupling

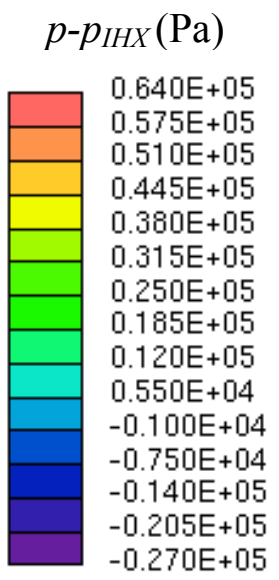

Figure 11: STAR-CD Predictions for Pressure, Relative to the IHX Inlet Boundary, at $t=0$.

Some interesting phenomena can be noted from the coupled simulation. At 200 seconds, the temperature gradients in the lower section of the plenum are quite steep. By 500 seconds, thicker temperature layers develop. At 1000 seconds, the fluid in the lower section of the plenum is warmer than the fluid above it, because the core outlet temperature is rising relatively sharply. Cooler fluid reaches the annular region above the IHX between 1000 and 2000 seconds. In the natural circulation phase of the transient, the core outlet temperature reaches a peak at approximately 2000 seconds in the fully coupled case, and approximately 2700 seconds in the uncoupled case. Beyond this peak, there is a sharp gradient in the axial temperature profile close to the core outlet, but the mid-region of the plenum is fairly uniform. After $2700 \mathrm{~s}$, the stratified layers exist primarily above the IHX inlet elevation.

\subsubsection{IHX Temperature and Flow}

IHX inlet and outlet temperatures for the uncoupled and coupled cases are shown in Figure 13 and Figure 14, respectively. For the uncoupled results shown in Figure 13, the IHX intermediate- and primary-side outlet temperatures both increase during the early part of the transient due to loss of flow in both loops. The rapid reduction in power and flow on the primary side then causes the IHX primary-side outlet to reduce in temperature because of heat being transferred to the IHX intermediate-side. Over time, the intermediate system as a whole heats up and this heat transfer is reduced. Around 1200 seconds, the IHX is approximately isothermal. 


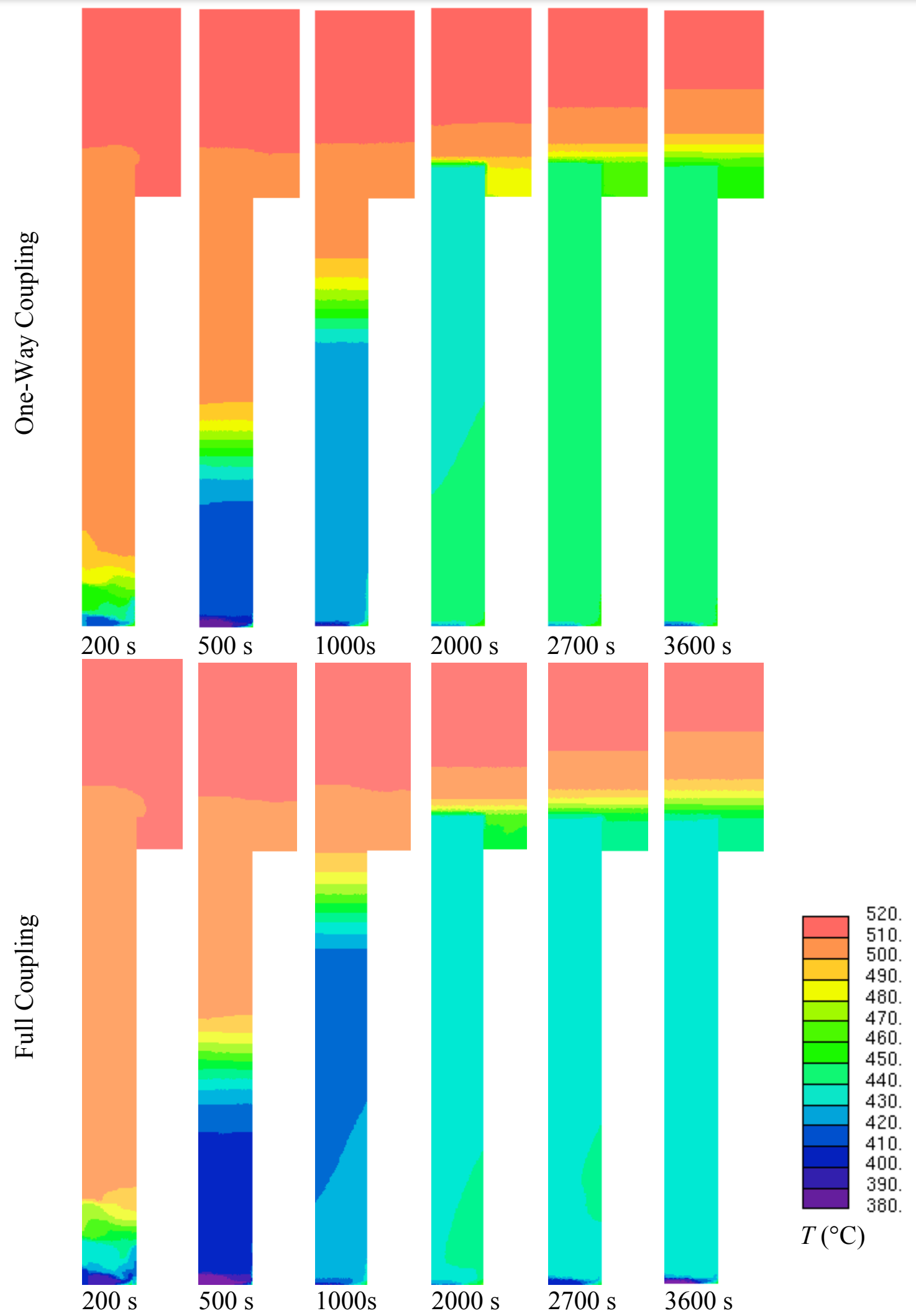

Figure 12: STAR-CD Prediction for Temperature Contours at Selected Times for One-Way Coupling (top) and Full Coupling (bottom) Codes. 
Beyond 1200 seconds, intermediate system temperatures begin to decline due in part to an intermediate reactor auxiliary cooling system (IRACS, labeled ACS in Figure 5) and in part due to cooling of the primary system by the reactor vessel auxiliary cooling system (RVACS). By 2800 seconds, the system has approached a nearly asymptotic cooling state and temperatures continue to steadily decline.

The coupled results shown in Figure 14 reveal a far more complex behavior. During the early part of the transient, the trends for the cold legs of the IHX (primary-side outlet and intermediate-side inlet) are similar to the uncoupled results except that the primary-side outlet heats faster. The reason for this is clear when the primary-side inlet temperature is compared. Due to thermal stratification in the outlet plenum, the IHX primary-side inlet temperature stays elevated for an extended period of time and does not begin appreciable decline until around 1200 seconds. This is consistent with the CFD temperature distributions shown in Figure 12.

Between 1600 and 2000 seconds, an unusual increase in the primary-side outlet temperature is predicted. This phenomenon can be understood by considering the flow rates on both the primary and secondary side, which are shown in Figure 15. During this time, the primary-side flow rate has dropped to approximately 5\%, resulting in longer transit times through the IHX. Even more significant, the secondary-side flow rate is stagnating during this time interval, with a minimum flow rate of $0.5 \%$ calculated at around 2300 seconds. At this point, the IHX is unable to reject heat to the intermediate system, and the hot coolant that had entered the primary side much earlier exits the primary side unchanged. The delay is also exaggerated due to the significant thermal inertia of the IHX structural components.

With heating of the IHX, natural circulation in the intermediate loop begins to increase slightly to a peak of approximately $1.5 \%$ shortly before 2800 seconds. This phenomenon seems to introduce a periodic behavior with multiple modes that depend on time constants in both the primary and intermediate systems.

Finally, because of the long initial heating period of the intermediate loop between 0 and 1400 seconds, the intermediate system becomes a heat source for the primary system rather than a heat sink. After 1600 seconds, coolant enters and intermediate-side of the IHX at a relatively high temperature and exits at a lower temperature. Furthermore, because of the significantly lower flow rates in the intermediate system, the IRACS may be ineffective as an emergency heat removal system, although higher overall temperatures may mitigate this. IRACS heat rejection rates were not compared in this initial analysis. 


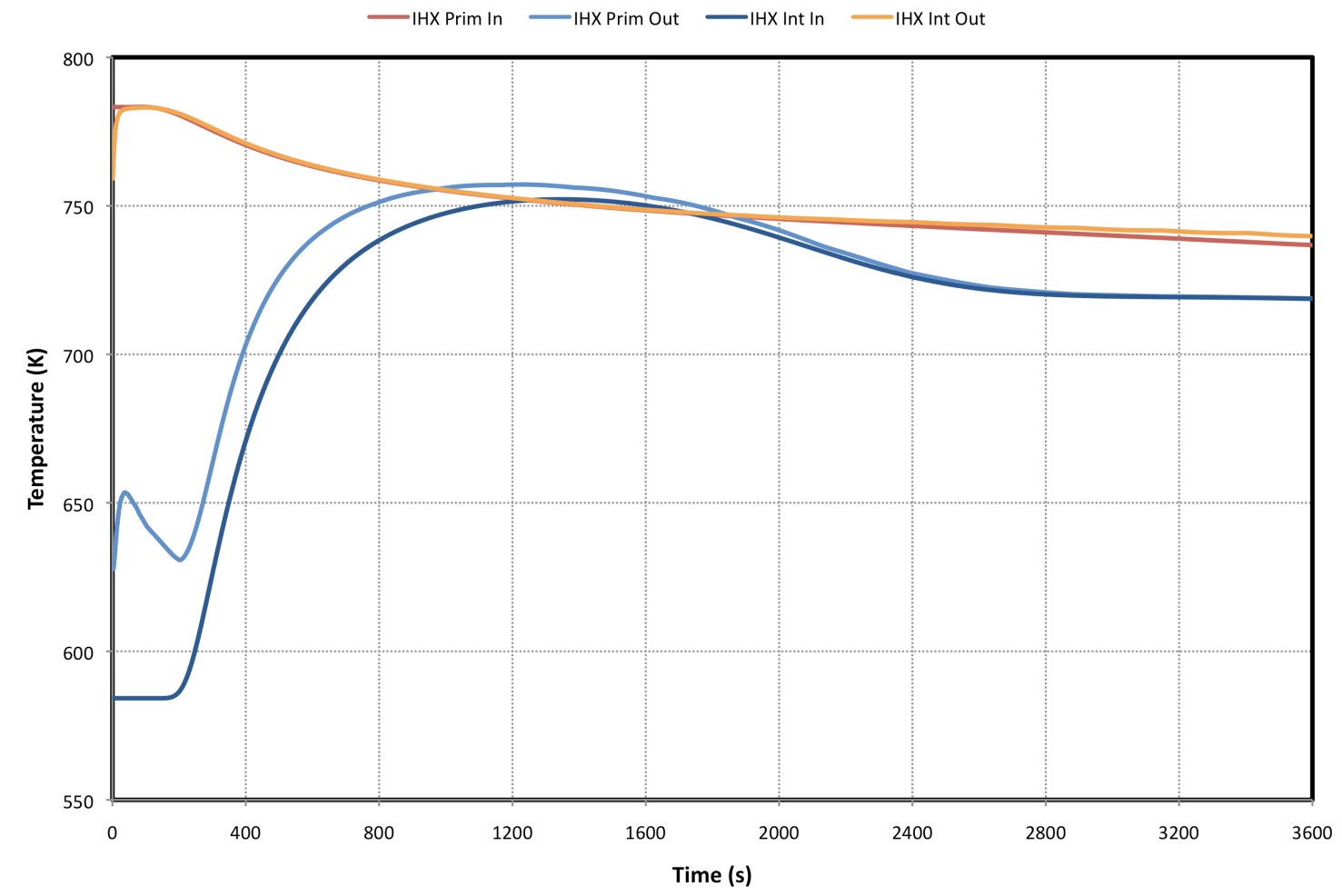

Figure 13: IHX Inlet and Outlet Temperatures for the Uncoupled Case.

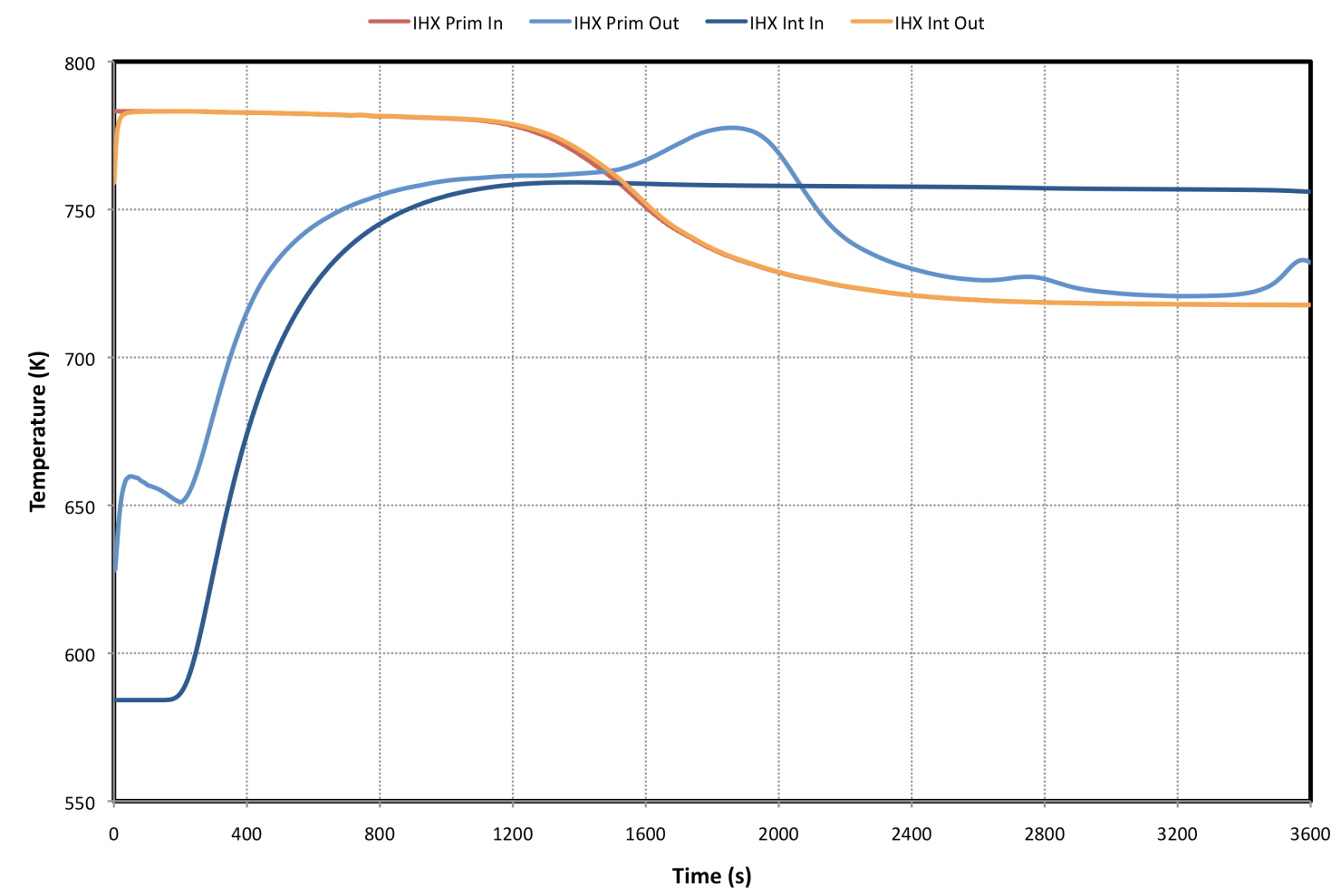

Figure 14: IHX Inlet and Outlet Temperatures for the Coupled Case. 


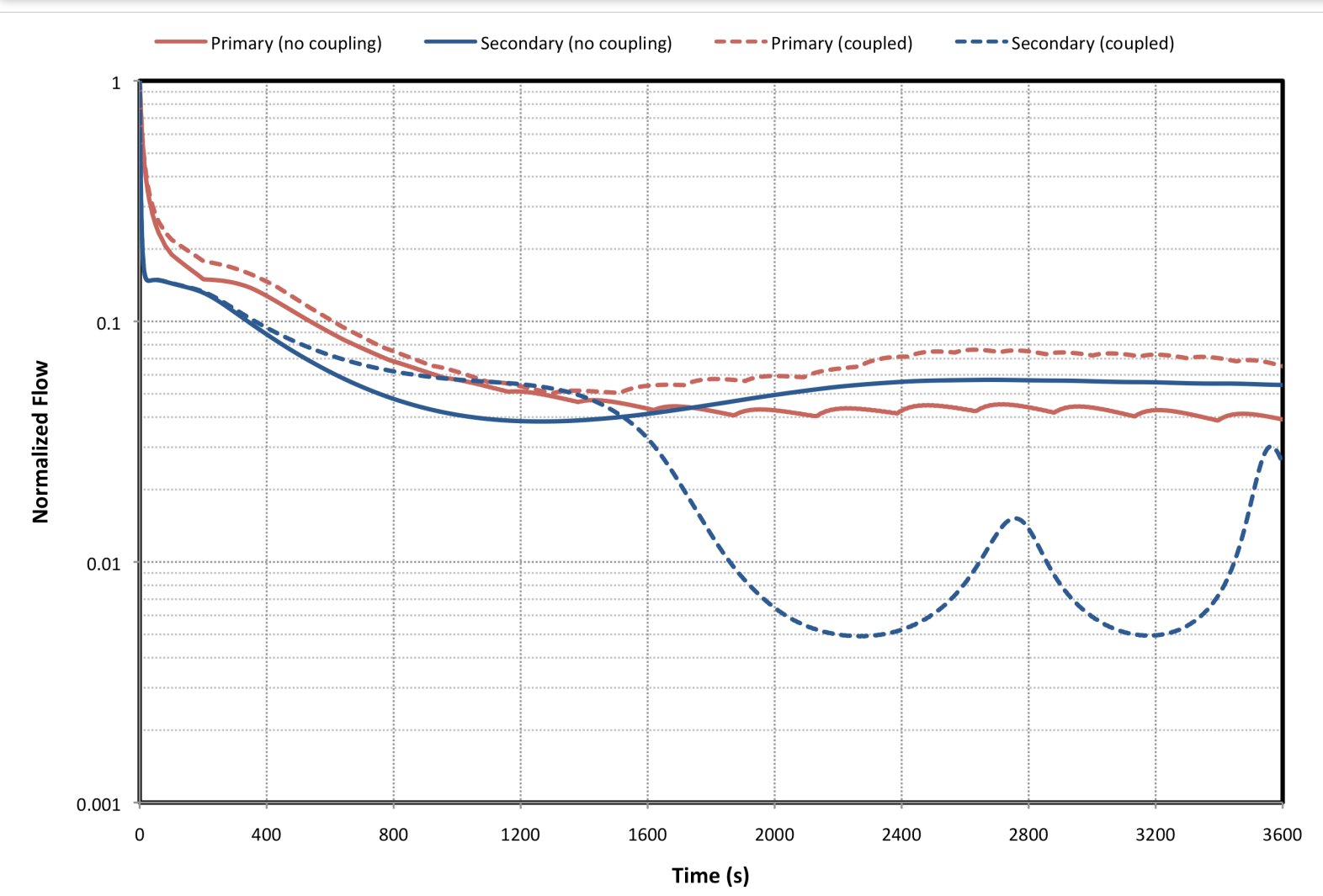

Figure 15: Normalized Primary and Secondary System Flow Rates for Both Coupled and Uncoupled Cases. Thermal stratification in the outlet plenum enhances primary system flow rates but causes flow stagnation in the secondary system.

\subsubsection{Core Temperatures and Flows}

Core inlet and outlet temperatures for the uncoupled and coupled cases are shown in Figure 16 and Figure 17, respectively. The most obvious difference is that the peak core outlet temperatures for the coupled case occur earlier and at a lower temperatures than the uncoupled case. In addition, core outlet temperatures decline faster after the peak is reached. This is contrary to the CERES results shown in Figure 3, in which much higher outlet temperatures are predicted. The source of this discrepancy is not known at this time.

Differences in the inlet and outlet temperatures are plotted in Figure 18. During the early part of the transient $(t<400 \mathrm{~s})$, there is a large transition in power and flow that leads to brief differences between the two temperature results. Since reactivity is dominated by the scram, power histories would be nearly identical. Both power and flow are changing rapidly during this time period. Slight differences in flow predictions may be contributing to outlet temperature variations. These differences are likely due to the initial development of thermal stratification in the outlet plenum. 


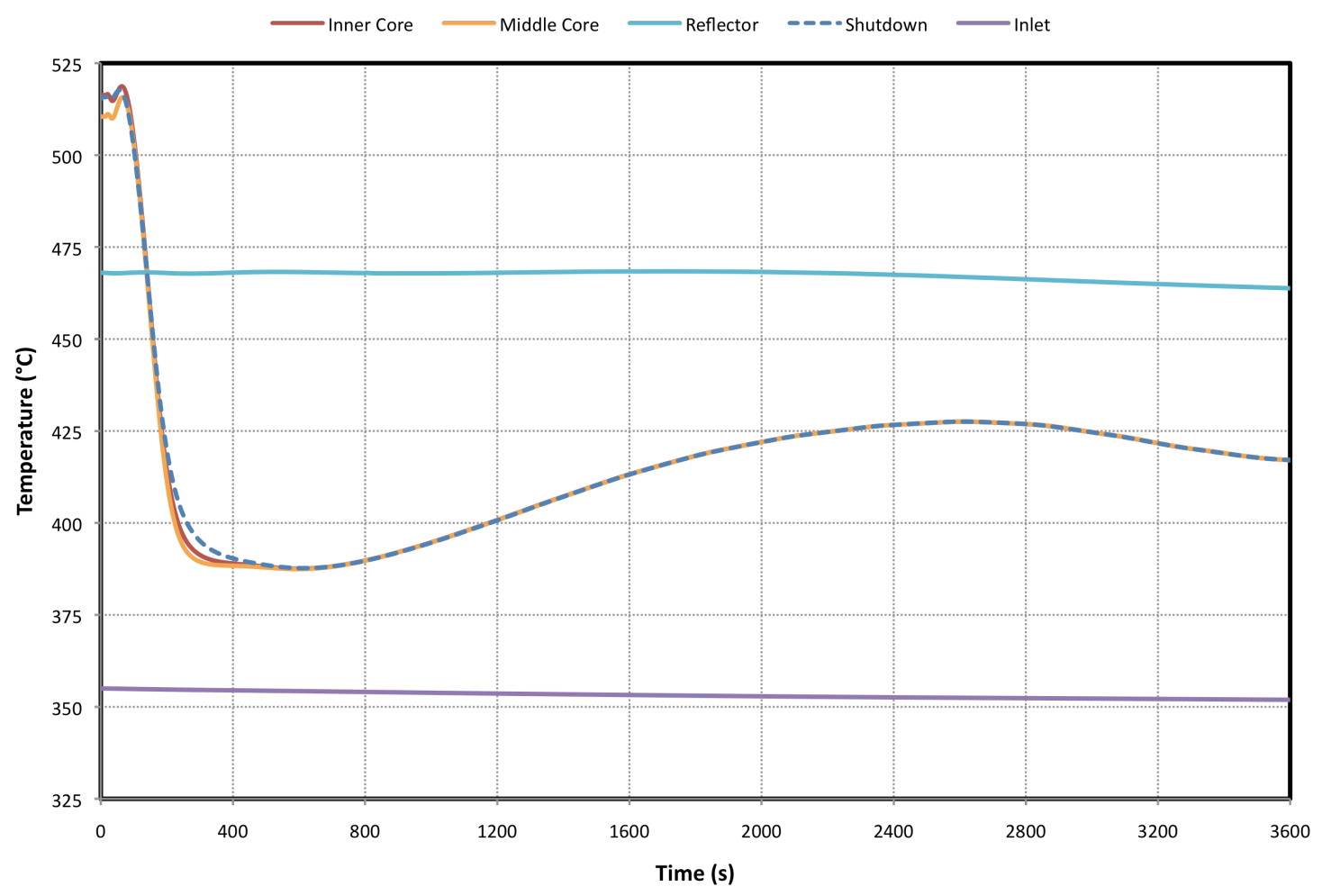

Figure 16: Core Inlet and Outlet Temperatures for the Uncoupled Case.

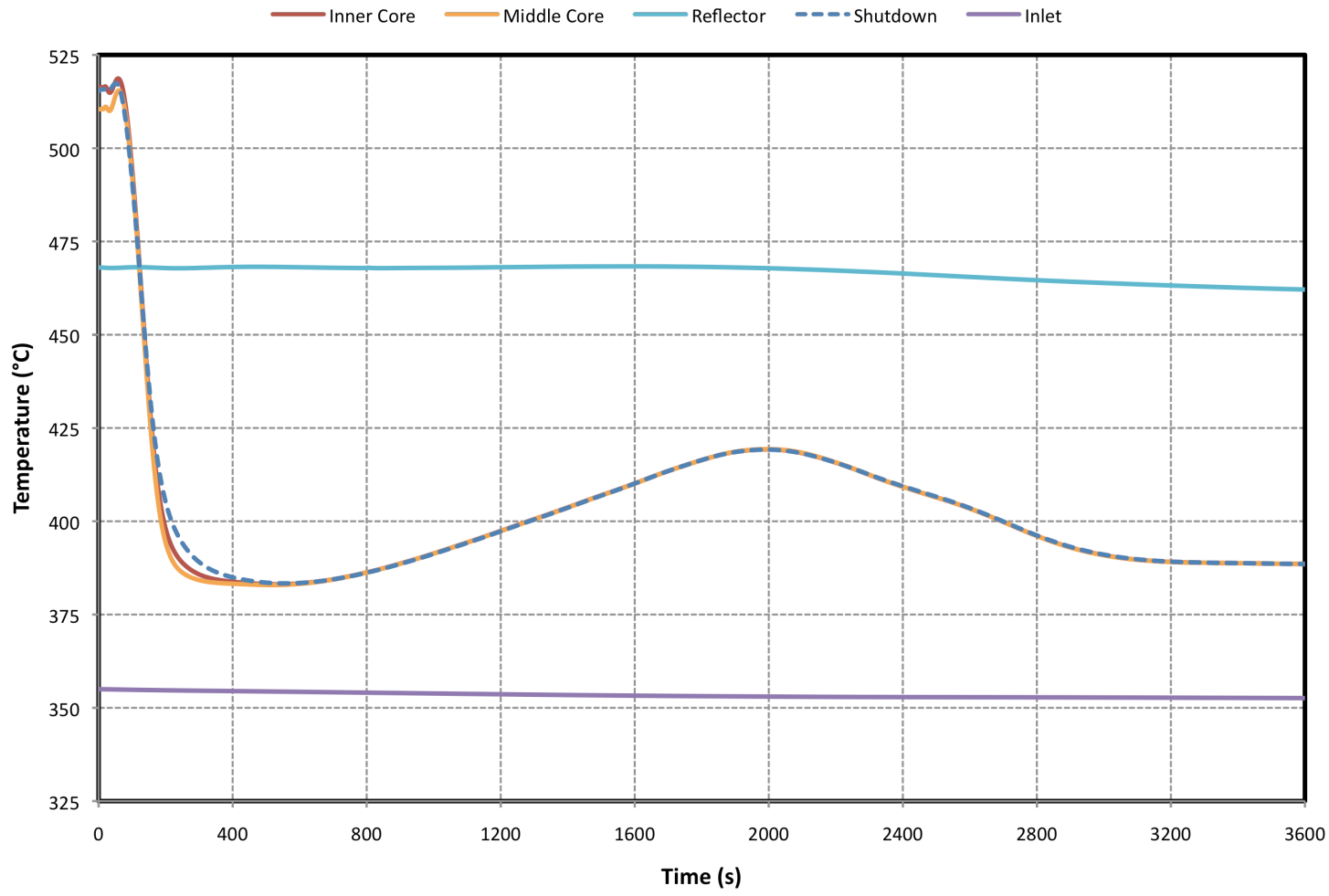

Figure 17: Core Inlet and Outlet Temperatures for the Coupled Case. 


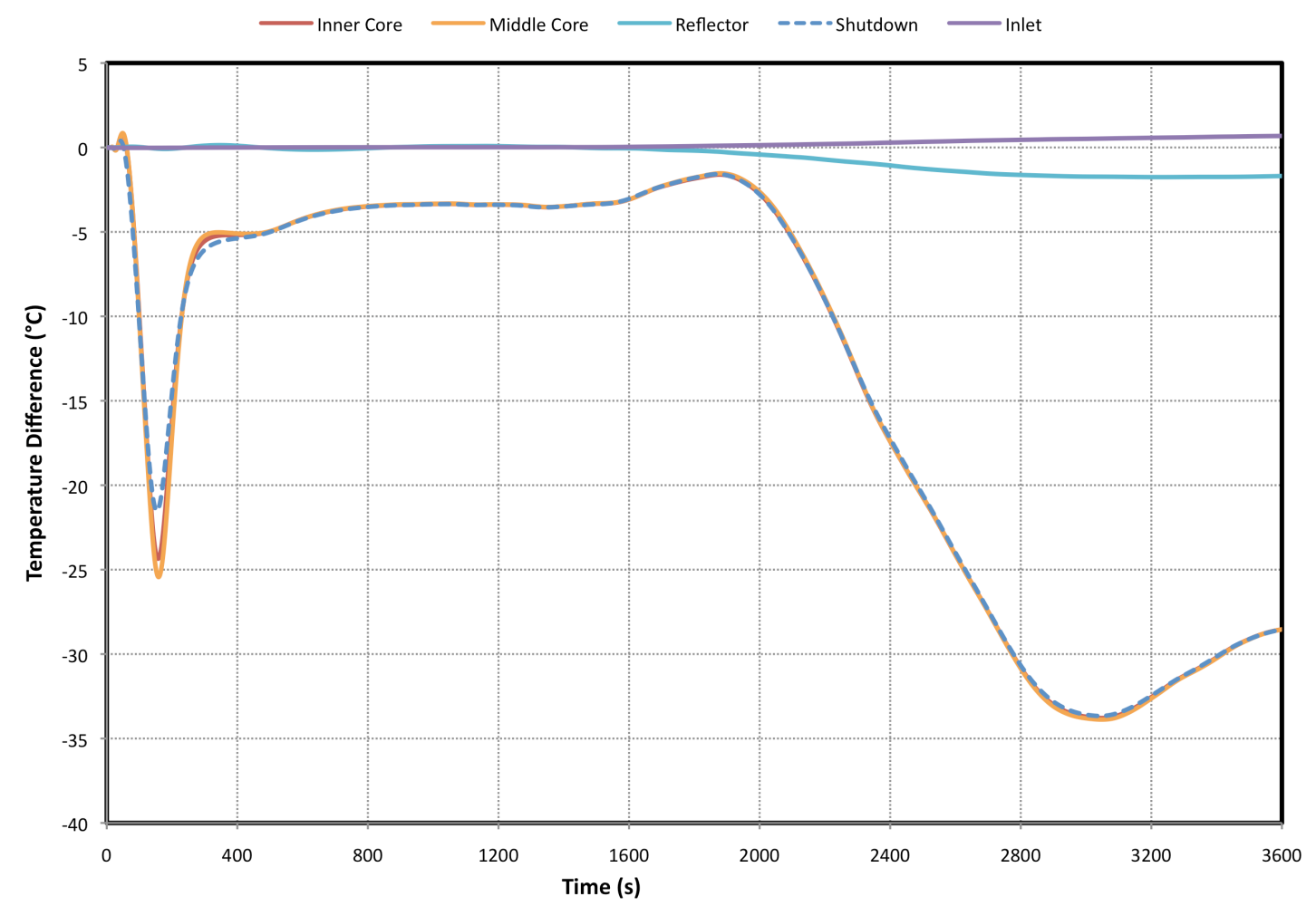

Figure 18: Core Inlet and Outlet Temperature Differences Between Coupled and Uncoupled Cases.

Between 400 and 2000 seconds, there is good agreement in the core outlet temperatures $\left(\Delta T<5^{\circ} \mathrm{C}\right)$. Beyond that time, however, the core outlet temperatures begin a faster decline in the coupled case than in the uncoupled case. This is due to a much faster rise in the natural circulation flow rates that develop in the latter parts of the transient when thermal stratification between the core outlet and IHX inlet has essentially ended (see Figure 12).

Core channel flow rates for the uncoupled and coupled cases are shown in Figure 19 and Figure 20, respectively. As stated above, primary system flow rates in the coupled case tend to increase in the second half of the transient, whereas those in the uncoupled case remain nearly flat. Estimates of the differences in core channel flow rates between the uncoupled and coupled models are shown in Figure 21. Between 2400 and 3600 seconds, flow in the coupled case is predicted to be approximately $75 \%$ higher than in the uncoupled case. This difference is responsible for the more rapid cooling of the core outlet temperatures.

Further interpretation of the temperature and flow differences between the two models would require are more detailed understanding of the role of the large radial shield in the $4 \mathrm{~S}$ model, which represents a very large thermal inertial just prior to the core inlet, and the impact the model changes have had on the RVACS heat rejection performance. Although this data is available, it was not analyzed for this comparison but may be reviewed in the future. 


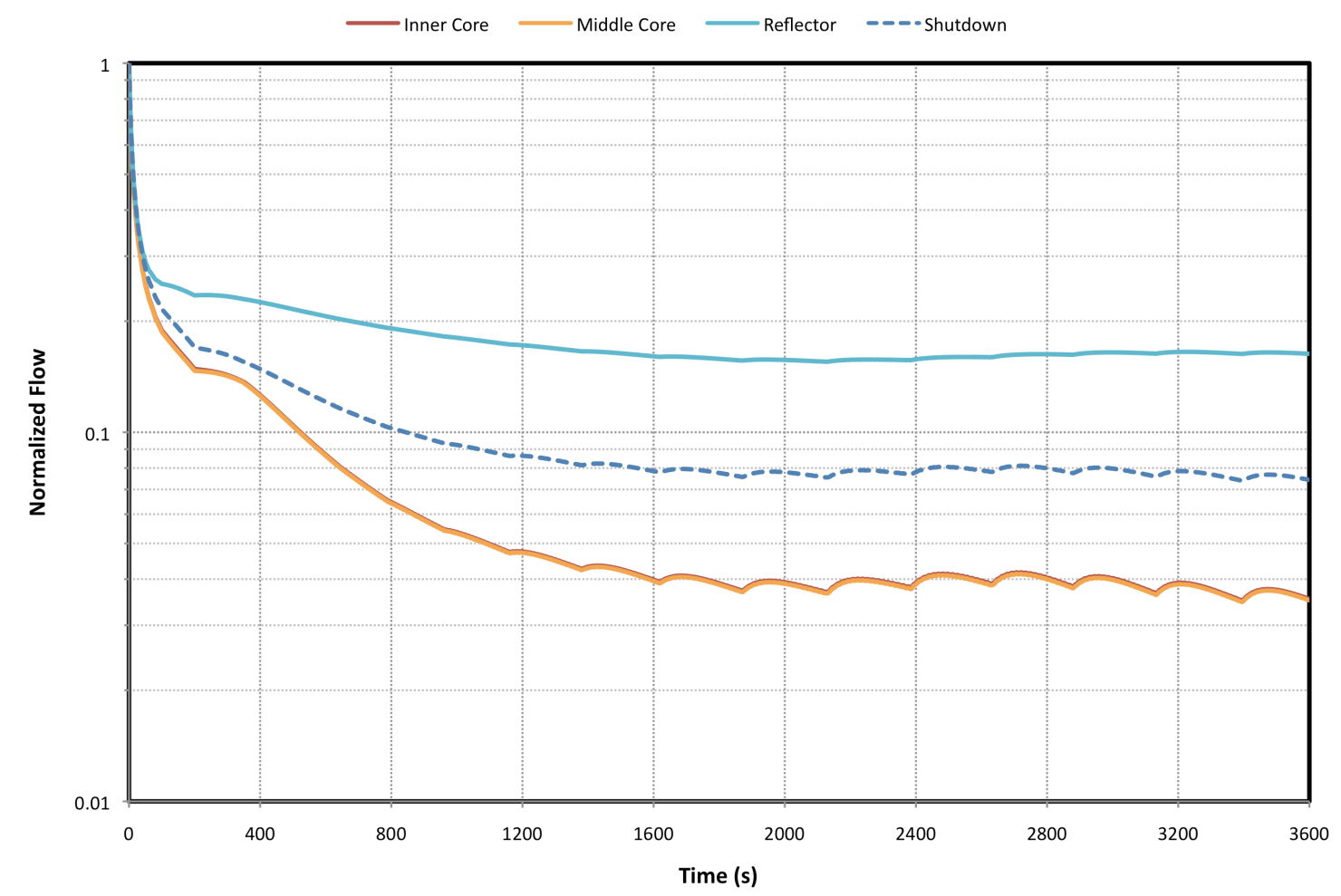

Figure 19: Core Channel Flow Rates for the Uncoupled Case.

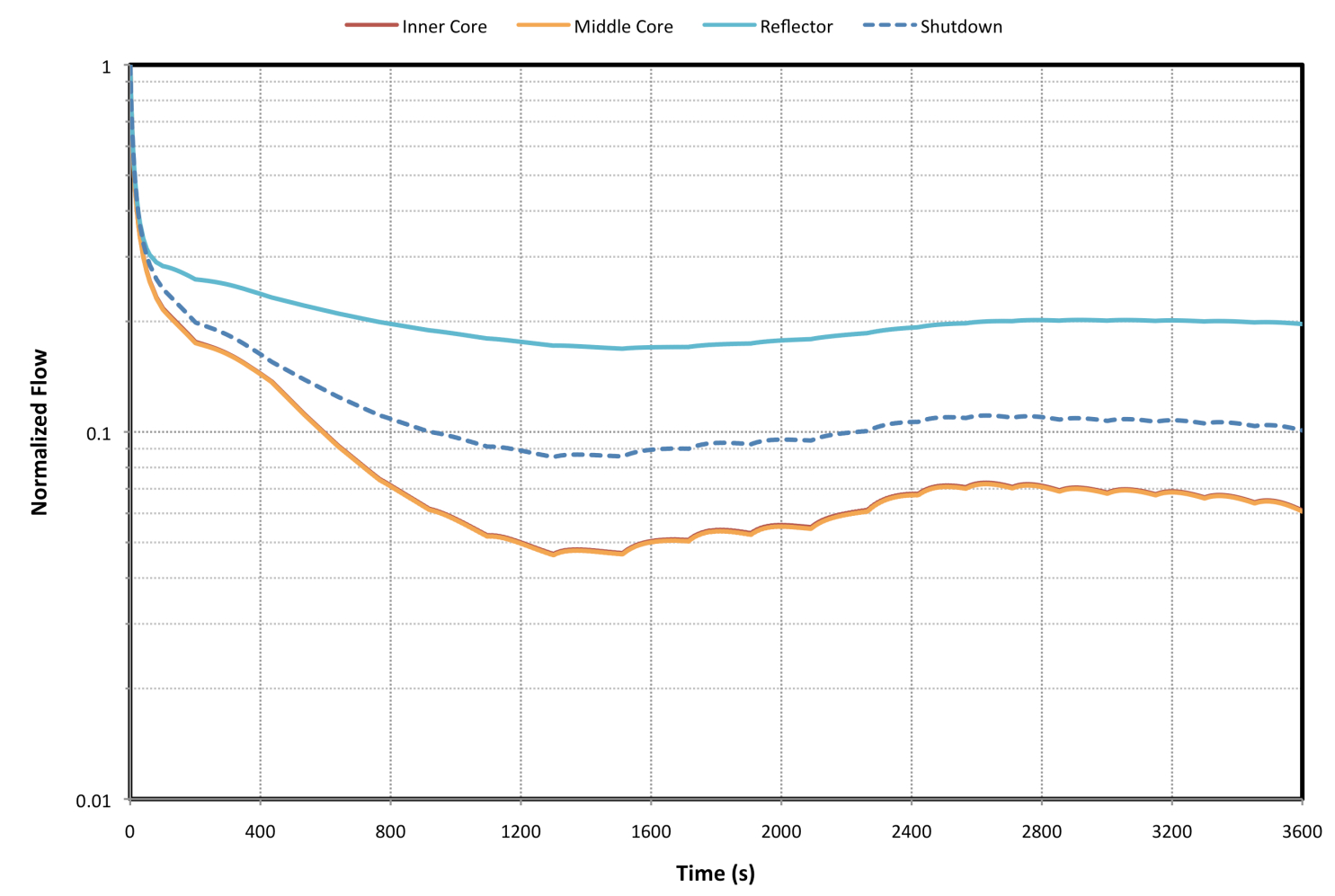

Figure 20: Core Channel Flow Rates for the Coupled Case. 


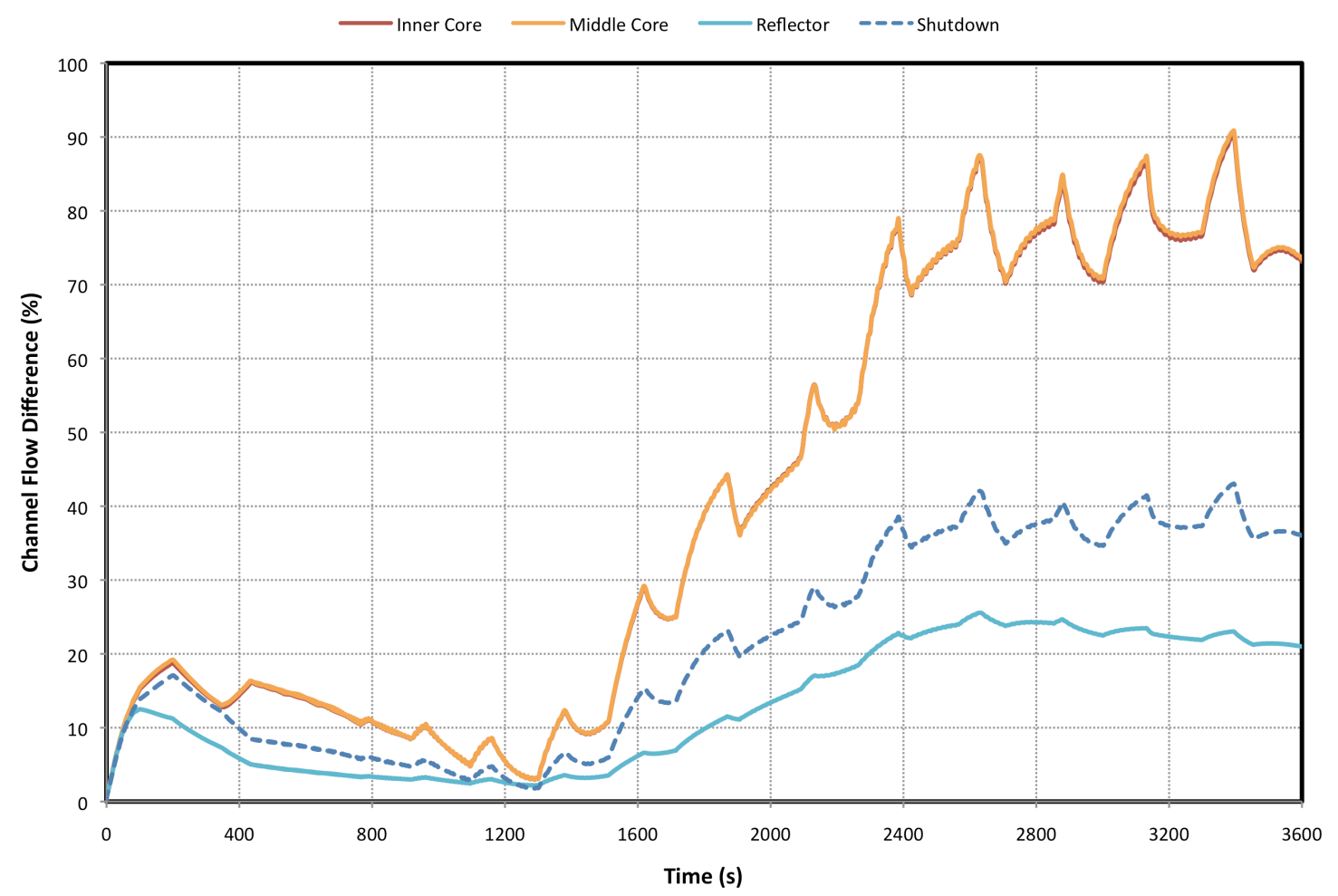

Figure 21: Core Channel Flow Differences Between Coupled and Uncoupled Cases.

\section{Summary}

From the results of the SAS4A/SASSYS-1 analysis using either the perfect mixing or the three-tier thermal stratification model reported in the earlier work, it is clear that such simple plenum models are insufficient to resolve the behavior of outlet plenum mixing and thermal stratification during a loss of flow transient where natural circulation is important. This work has demonstrated that with a proper coupling approach, a high-fidelity CFD tool can be used to resolve the important flow and temperature distributions in a reactor outlet plenum while still maintaining the whole-plant safety analysis capabilities of a systems analysis code.

Temperature and flow rate changes in the primary system and core were anticipated and observed as a result of resolving the thermal stratification in the outlet plenum. What was not anticipated, however, was the far-reaching impact that resolving thermal stratification would have on the whole plant. In the uncoupled case, the intermediate system acts as a heat sink for the duration of the simulation. In the coupled case, however, the high temperatures at the IHX inlet due to thermal stratification heat the intermediate system to the point that it eventually becomes a source of heat for the primary system. The results also suggest that flow stagnation in the intermediate system is possible, raising questions about the effectiveness of the IRACS during a protected loss of flow accident scenario.

Future application of these methods will include analysis of the Phénix end-of-life natural convection test that is part of an IAEA international benchmark and analysis of the EBR-II SHRT or PICS (plant inherent control system) tests. In the case of the Phénix natural 
circulation test, a steam generator dry-out triggers a protected loss of flow sequence in which natural circulation provides core cooling. Thermocouple data in the outlet plenum is available for validation. In the case of EBR-II testing, thermocouple data shows thermal stratification in the cold pool during a variety of test sequences.

\section{References}

1. A. Siegel, T. Tautges, A. Caceres, D. Kaushik, and P. Fischer, "Software Design of SHARP," Proc. Joint Int'l Topical Mtg. on Mathematics \& Computation and Supercomputing in Nuclear Applications, Monterey, California, April 15-19, 2007.

2. S. H. Fistedis, ed., "The Experimental Breeder Reactor-II Inherent Safety Demonstration," Nuclear Engineering and Design (special issue), 101, 1987.

3. Fast Reactor Database, 2006 Update, IAEA-TECDOC-1531, International Atomic Energy Agency, December 2006. (Available on-line via http://www-pub.iaea.org/MTCD/ publications/PDF/te_1531_web.pdf.)

4. J. E. Cahalan, A. M. Tentner, and E. E. Morris, "Advanced LMR Safety Analysis Capabilities in the SASSYS-1 and SAS4A Computer Codes," Proc. of the International Topical Meeting on Advanced Reactors Safety, American Nuclear Society, Vol. 2, pp. 1038-1045, Pittsburgh, PA, April 17-21, 1994.

5. Y. Nishi, N. Ueda, I. Kinoshita, A. Miyakawa, M. Kato, "Verification of the Plant Dynamics Analytic Code CERES using the Results of the Plant Trip Test of the Prototype Fast Breeder Reactor MONJU," Proceedings of ICONE14, Miami, Florida, July 17-20, 2006.

6. T. H. Fanning, F. E. Dunn, and Y. Nishi, "Development of 4S and Related Technologies: Comparison of Transient Accident Sequences Between the SAS4A/SASSYS-1 and CERES Reactor System Analysis Codes," Proc. Int'l Congress on Advances in Nuclear Power Plants (ICAPP 2009), Tokyo, Japan, May 10-14, 2009.

7. STAR-CD Methodology Manual v4.12, CD-adapco Group, Melville, NY, 2010.

8. T. H. Fanning and T. Sofu, "Modeling of Thermal Stratification in Sodium Fast Reactor Outlet Plenums During Loss of Flow Transients," Proc. International Conference of Fast Reactors and Related Fuel Cycles (FR 2010), Kyoto, Japan, December 7-11, 2009.

9. American National Standard Decay Heat Power in Light Water Reactors, ANSI/ANS-5.1-2005, American Nuclear Society, 2005. 